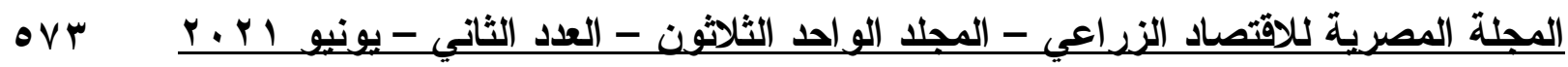
دراسة تحليلية للوضع التنافسي لصادرات الفراولة المصرية في أهم الأسواق العالمية

د/ إيهاب محمد صبري

دكتور
د/ دينا فاروق عناني

باحث

معهز بحوث الاقتصاد الزراعي - مركز البحوث الزراعية

Received : 20 / 7 / 2021 ,

Accepted : 18 / 9 / 2021

المستخلص

تتاول البحث التعرف على الأوضاع التتافسية للفر اولة المصرية داخل أهم أسو اقها الخارجية، وسوف

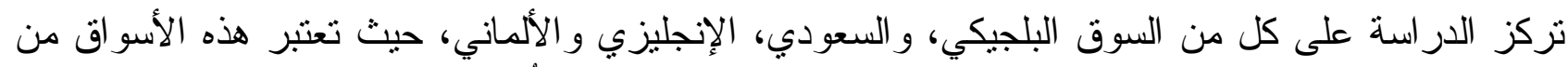
أهم الأسواق المستوردة للفر اولة المصرية على مستوى العالم، حيث قدر إجمالي كمية صادر ات الفر اولة الإنة

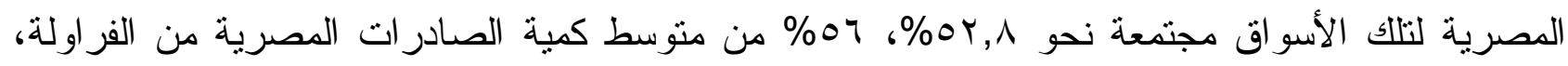

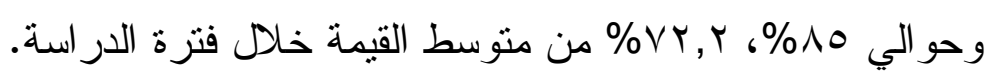

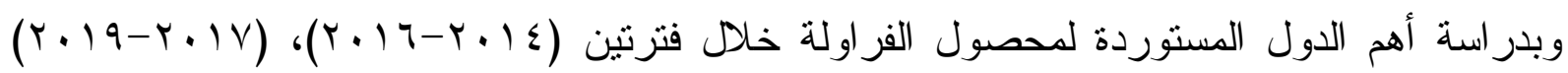
ومن هذا المنطلق سيتم در اسة كل سوق من هذه الأسواق لكل محصول لتحديد أهم المنافسين لمصر وكذلك

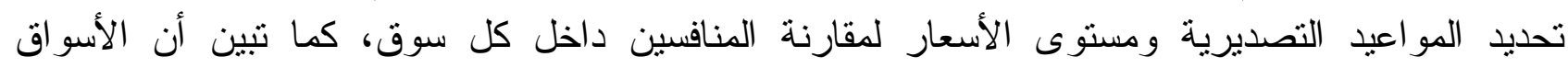

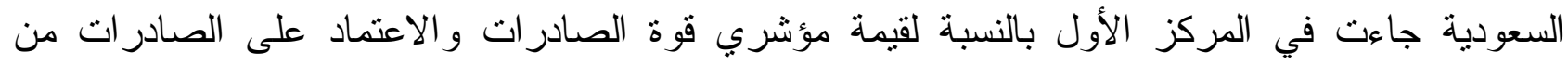

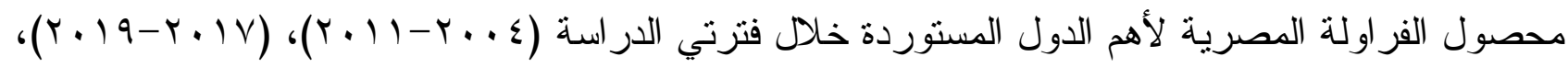
يليها كل من بلجيكا، إنجلتر ا، ألمانيا؛ الأمر الذي يدل على أن كل من أسواق السعودية، بلجيكا و ألمانيا

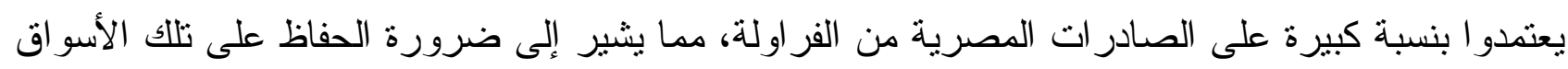

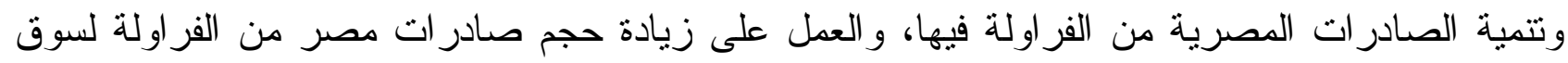
ألمانيا.

الكلمات المفتاحية: الأنصبة السوقية، المواعيد التصديرية، المنافسة السعرية.

مقدمة

يعتبر محصول الفراولة من المحاصيل البستانية الهامة في مصر ذات الاستخدامات المتعددة حيث يمكن استهلاكها مباشرةً أو إدخالها في عدد من الصناعات الغذائية وهي من الزر اعات ذات القيمة الزئة الزر اعية

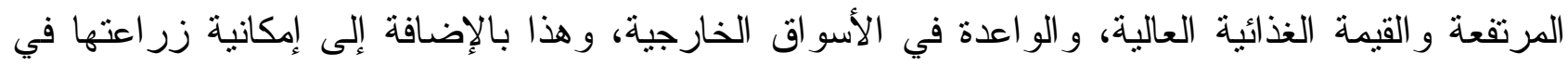

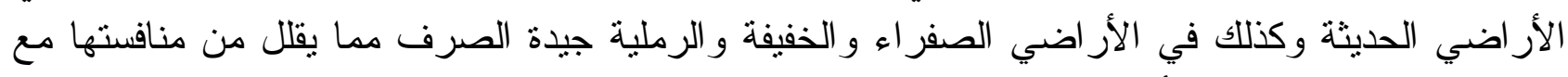
المحاصيل الرئيسية على الأر اضي القديمة و المستصلحة، و التي تتصف بحساسيتها الثديدة للظروف الجية الجوية خاصة درجات الحر ارة المرتفعة(0). تعتبر الفر اولة من أهم المحاصيل التي اتجهت مصر لإنتاجها بمعدلات كبيرة وهى من المحاصبل ذات العائد الكبير وتصدر إما طازجة أو مجمدة أو مصنعة، ولمصر ميزة تتافسية في إنتاجها وتصدر الفر اولة المبكرة للدول الأوروبية حيث يبدأ موسم التصدير في شهر نوفمبر وحتى فبر اير وبالنسبة للدول العربية فيبدأ

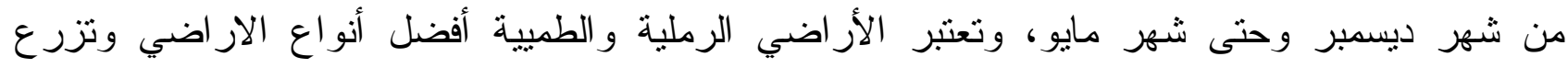

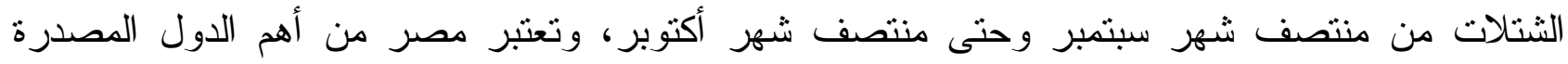
للفراولة وتأتي في المركز الحادي عشر علي العالم، وتعتبر الفراولة من اهم المحاصيل التصديرية غير ونير التقليدية الو اعدة.

كما تعتبر الفراولة من المحاصيل البستانية التصديرية الواعدة، و التي ينز ايد الطلب العالمي عليها، و على الرغم من ذلك لُوحظ عدم الاهتمام الكافي به كمحصول تصديري و اعد، وتمثل ذلك في انخفاض نسبة 


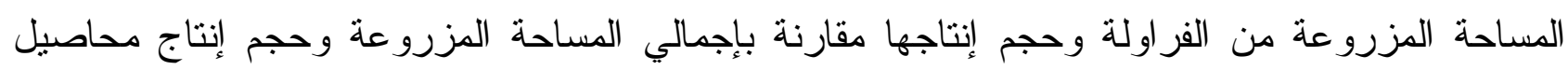

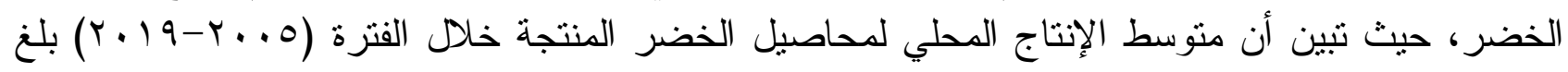

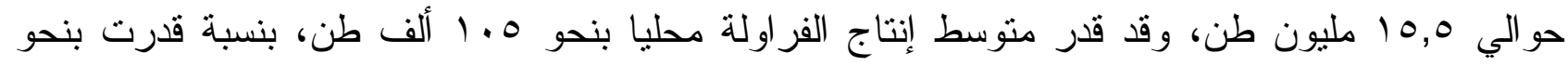

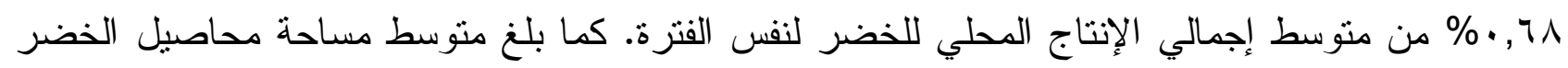

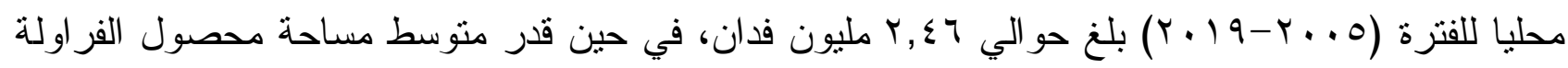

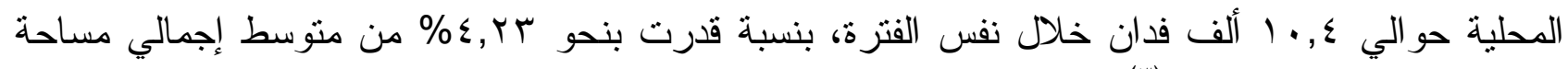

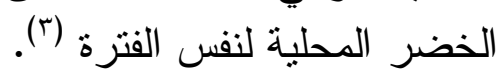
وتهتم هذه الدراسة بدراسة الأهمية النسبية لإنتاج محصول الفراولة محليا وعالميا، وكذلك دراسة

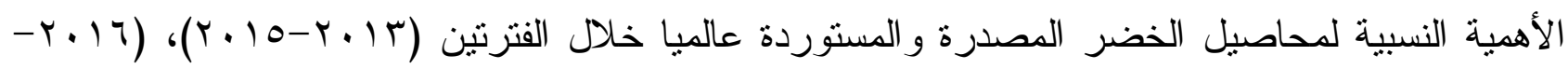

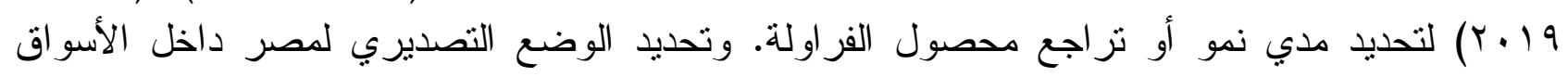

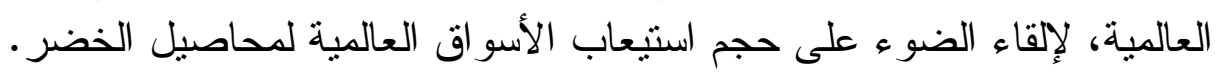

مشكلة البحث

تتمثل مشكلة البحث في انخفاض صادر ات مصر من الفراولة المصرية في في معظم الأسو اق المستوردة،

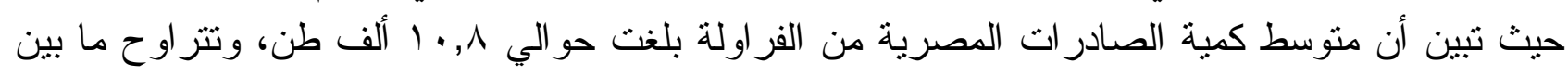

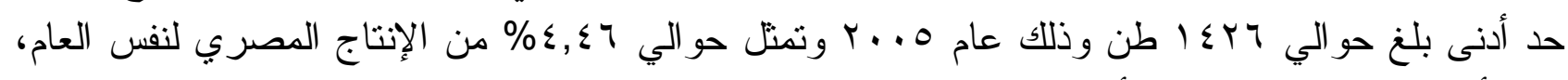

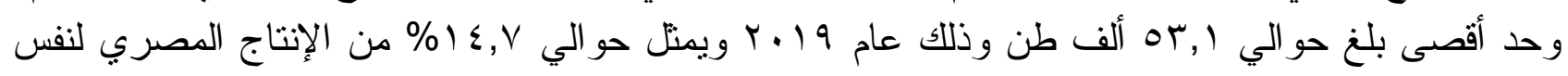

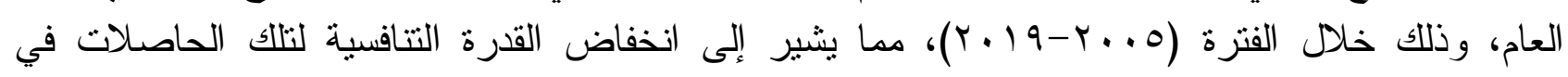

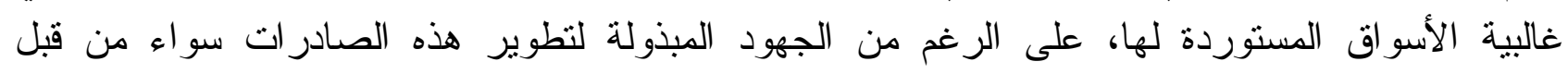

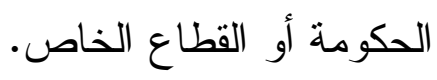

الهـف من البحث

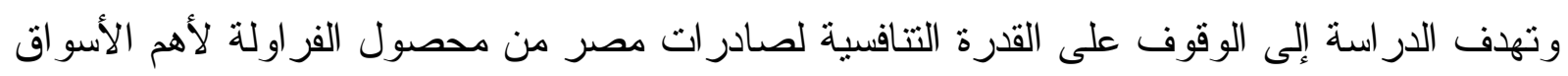

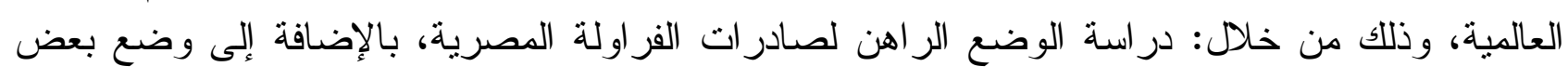

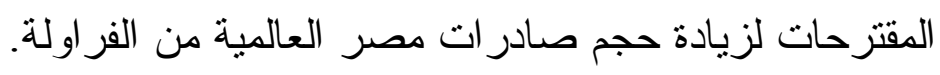

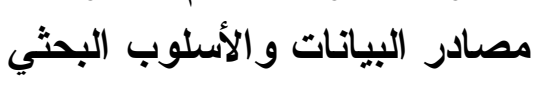

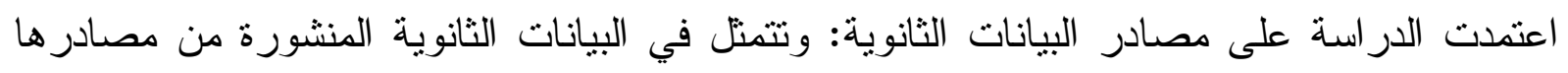

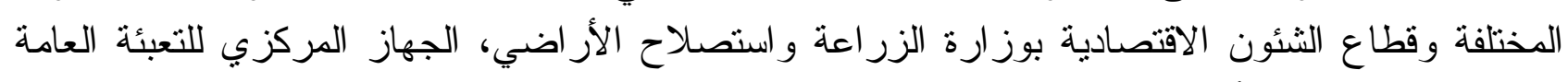

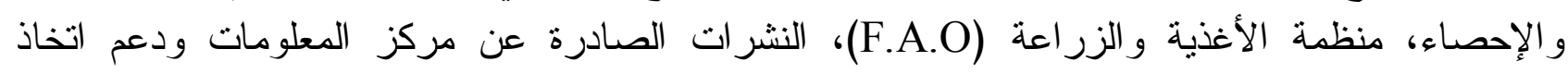

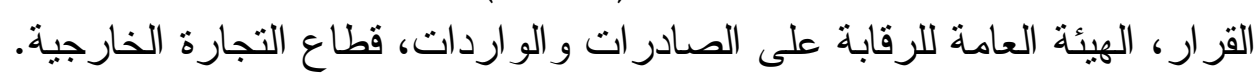

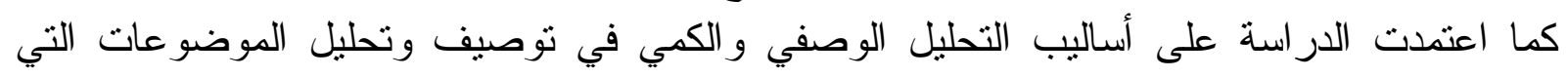

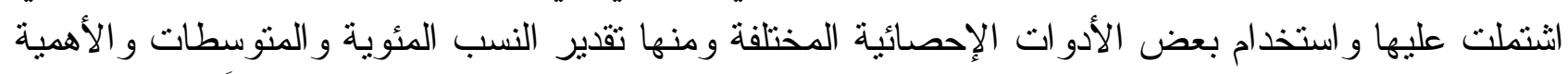

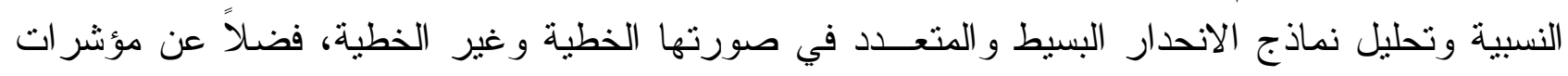

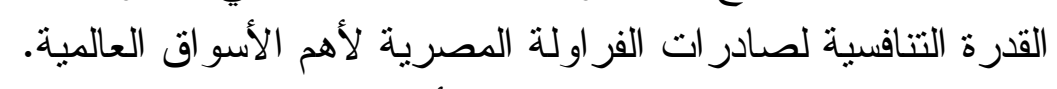

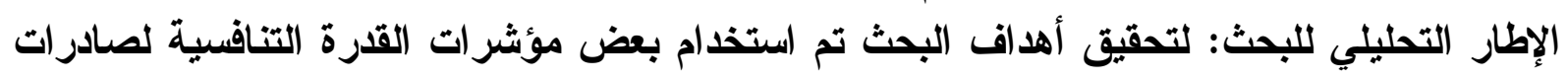

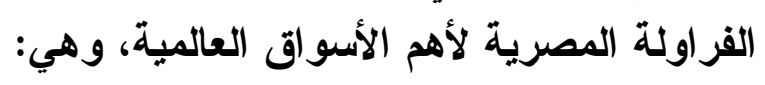
1-مؤشر النصيب السوقي:

يستخدم مؤشر النصيب السوقي لقياس التتافية على المستوى السلعي بالنسبة لإجمالي العالم، وبالتالي يبين مدى القدرة على الوفاء بمنطلبات التصدير، وكفاءة العمليات التسويقية، ويعتبر ارتفاعه أحد الأهداف لإلفي 
الرئيسية لتوسيع حجم التجارة الخارجية لأي دولة، وكلما حصلت الدولة المصدرة للمحصول على نسبة مئوية

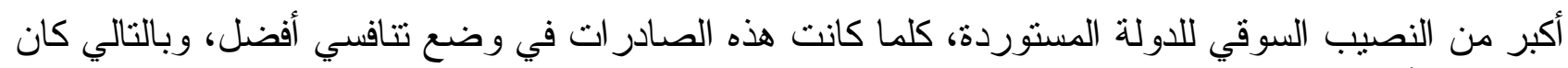

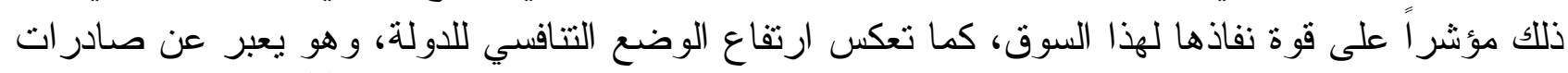

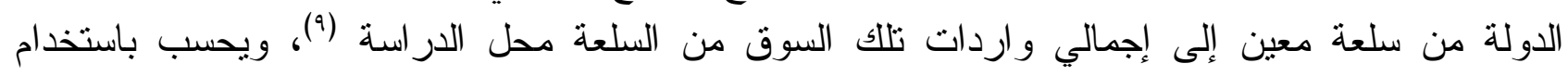

\section{$\mathrm{MsHji}=(\mathrm{Xjci} / \mathrm{Mcwi}) * 100$}

المعادلة التالية.

$$
\text { هيث: }
$$

r - بؤشر المنافسة السعرية:

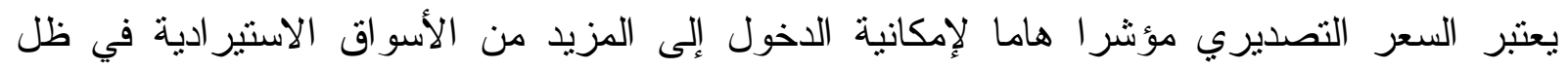

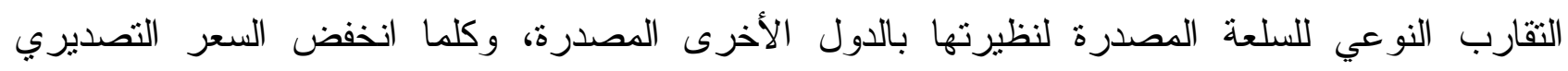
بالمقارنة بنظيره بالدول الأخرى المنافسة، فأن ذلك يعنى وجود ميزة سعرية للسلعة المصدرة وقدرة تتافسية أكبر للمحصول المصدر، و السعر التصديري لا يعكس فقط التكاليف الإنتاجية للسلعة، ولكنه يتأثز بعو امل اخرى منل تكاليف النقل و الضر ائب ومو عد التصدير و غيرها من التكاليف المرتبطة بعملية التصدير و التي اصبحت أكثر تأثير اً على السعر التصديري من التكاليف الإنتاجية(؟)، ويتم تقدير مؤشر التنافسية السعرية $\mathbf{P A j}=\mathbf{P e} / \mathbf{P c}$ على النحو التالي: تلتئ

PAj Pe Pc

ب-مؤشر قوة التصدير لمحصول الفراولة المصرية في أهم الأسواق الاستير ادية:

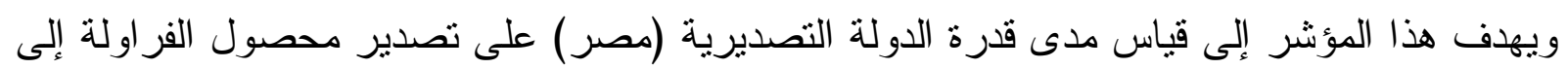

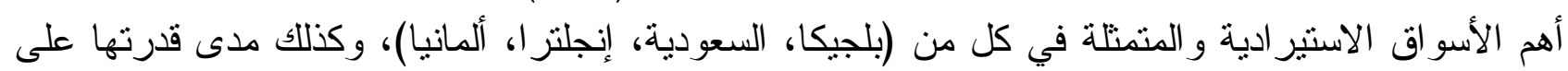

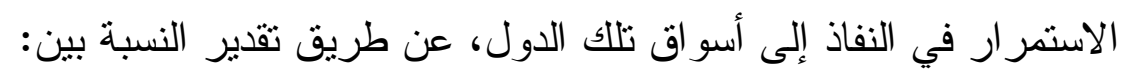

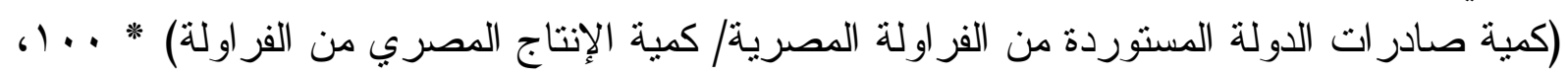

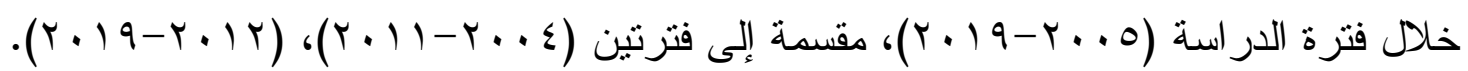
وكلما زادت قيمة هذا المؤشر فأنه يشير إلى أن مصر تقوم بتصدير كميات كبيرة بالنسبة لإنتاجها من

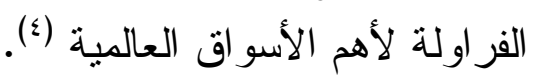

ع - مؤشر الاعتماد على تصدير الفراولة المصرية في أهم الأسواق الاستيرادية:

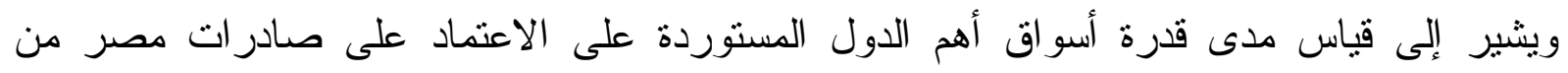
محصول الفراولة، وكلما زادت قيم هذا المؤشر دل ذلك على الأمر الذي بدل فلى على أنى أن الأسواق المستوردة

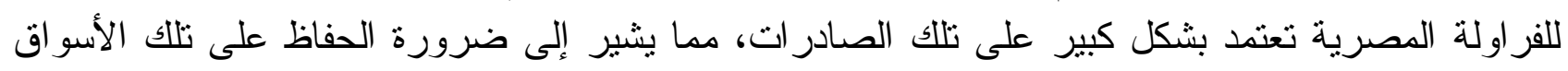
وتتمية الصادر ات المصرية من الفر اولة فيها، و العمل على زيادة حجم صادر ات مصر من الفر اولة لها (ءٔ). 
○V 7 در اسة تحليلية للوضع التنافسي لصادرات الفراولة المصرية في أهم الأسواق العالمية

ويتم قياس مؤشر الاعتماد على التصدير من خلال المعادلة:

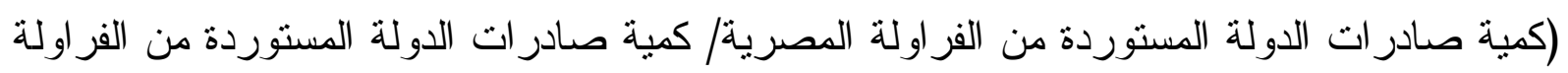

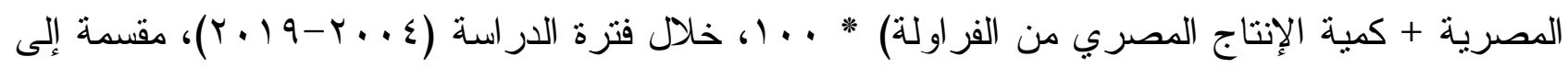

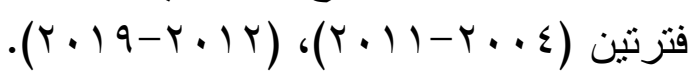
مناقشة وتحليل النتائج

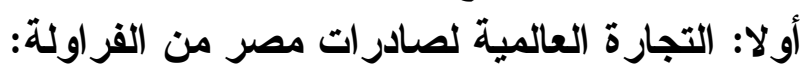

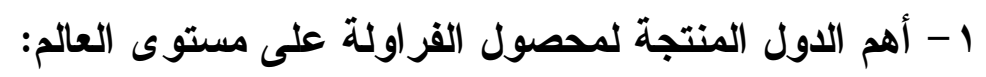

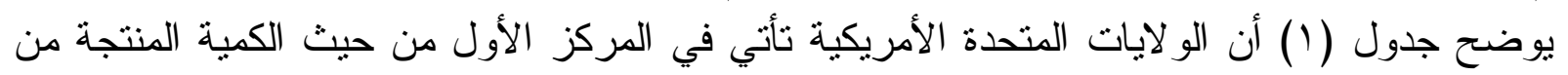

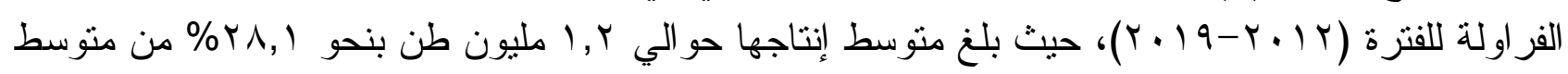

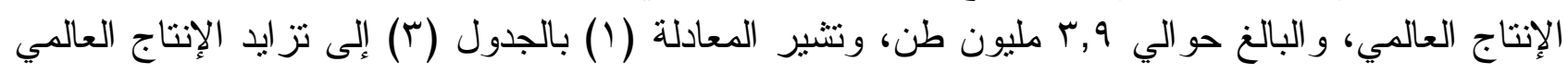

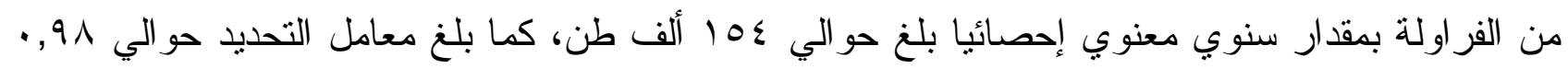

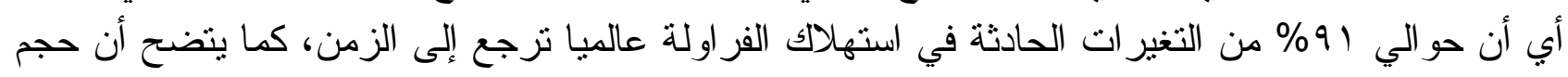

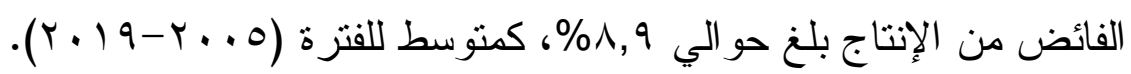

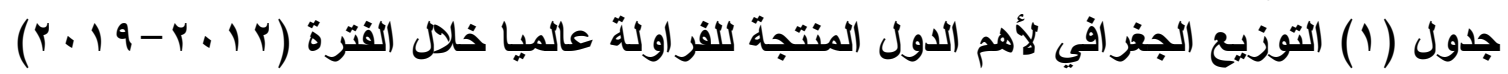

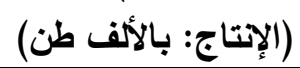

\begin{tabular}{|c|c|c|c|c|c|c|c|c|c|c|}
\hline الأهمية & المتوسط & 2019 & 2018 & 2017 & 2016 & 2015 & 2014 & 2013 & 2012 & الاولة \\
\hline 28.1 & 1118 & 1292 & 1270 & 1148 & 1109 & 1090 & 1053 & 1004 & 978 & أمريكا \\
\hline 7.34 & 292 & 275 & 264 & 281 & 269 & 335 & 321 & 335 & 264 & إسبانيا \\
\hline 5.71 & 227 & 350 & 292 & 261 & 250 & 211 & 200 & 155 & 150 & تركيا \\
\hline 5.17 & 206 & 232 & 204 & 192 & 203 & 205 & 202 & 203 & 205 & كوريا \\
\hline 5.07 & 202 & 165 & 185 & 180 & 235 & 227 & 221 & 207 & 199 & روسيا \\
\hline 4.81 & 192 & 178 & 185 & 191 & 191 & 191 & 196 & 198 & 203 & اليابان \\
\hline 4.79 & 191 & 227 & 233 & 207 & 176 & 192 & 163 & 177 & 150 & المكسيك \\
\hline 4.54 & 181 & 177 & 199 & 201 & 175 & 194 & 185 & 186 & 131 & بولندا \\
\hline 4.00 & 159 & 238 & 243 & 200 & 174 & 128 & 100 & 105 & 80 & مصر \\
\hline 3.91 & 156 & 154 & 163 & 156 & 161 & 143 & 147 & 168 & 155 & إيطاليا \\
\hline 3.68 & 147 & 141 & 355 & 135 & 120 & 112 & 119 & 106 & 91 & المغرب \\
\hline 3.64 & 145 & 157 & 159 & 150 & 159 & 173 & 147 & 119 & 91 & ألمانيا \\
\hline 2.21 & 48 & 47 & 47 & 44 & 47 & 51 & 52 & 53 & 45 & فُرنسا \\
\hline 2.17 & 47 & 57 & 58 & 53 & 41 & 48 & 46 & 36 & 33 & أوكرانيا \\
\hline 2.05 & 42 & 55 & 57 & 50 & 42 & 48 & 35 & 27 & 21 & روسيا البيضاء \\
\hline 2.05 & 81 & 103 & 110 & 105 & 92 & 74 & 69 & 53 & 47 & إنجلتر | \\
\hline 2.01 & 40 & 43 & 43 & 42 & 43 & 39 & 39 & 37 & 36 & هو'ندا \\
\hline 0.88 & 35 & 44 & 44 & 41 & 40 & 33 & 28 & 25 & 25 & تشيلى \\
\hline 0.86 & 34 & 47 & 43 & 44 & 41 & 33 & 18 & 23 & 27 & كولومبيا \\
\hline 0.55 & 22 & 33 & 36 & 38 & 33 & 35 & 0 & 0 & 0 & صربيا \\
\hline 10.5 & 418 & 403 & 409 & 423 & 405 & 415 & 441 & 435 & 414 & دول أخري \\
\hline 100 & 3982 & 4367 & 4597 & 4137 & 4002 & 3973 & 3779 & 3651 & 3349 & الإحمالي \\
\hline
\end{tabular}

source: www.faostat.org

كما تأتى كل من دول إسبانيا، نزكيا، كوريا، روسيا في المركز الثاني و الثالث و الر ابع و الخامس حيث

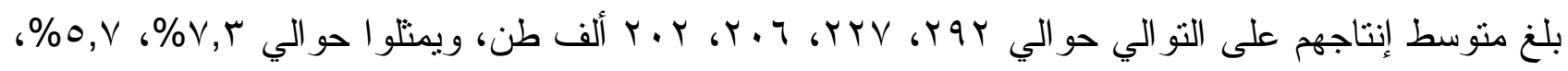

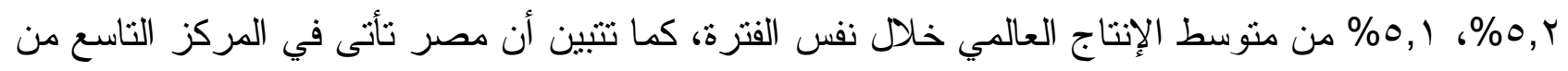




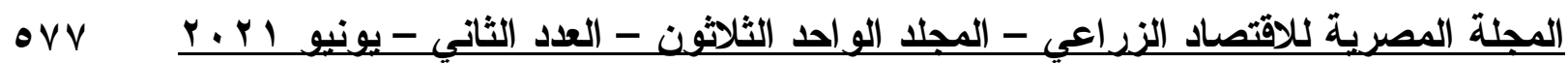

حيث مساهمتها في الإنتاج العالمي لمحصول الفراولة، حيث بلغ منوسط إنتاجها حو الي 109 ألف طن تمثل نحو ؟ ٪ من منوسط الإنتاج العالمي الفر اولة خلال نفس الفترة.

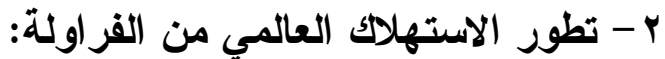

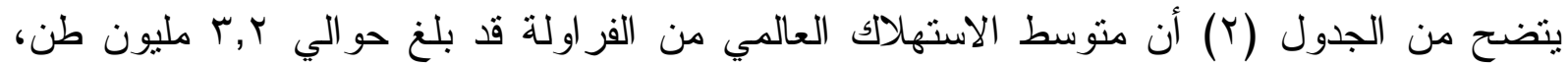

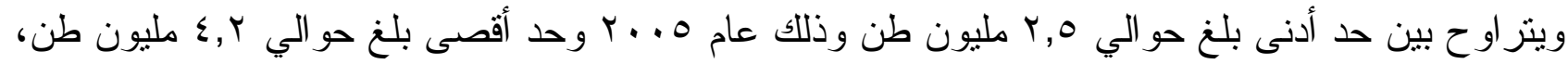

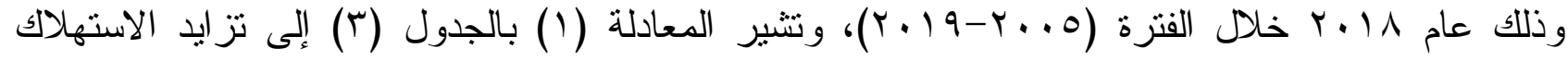

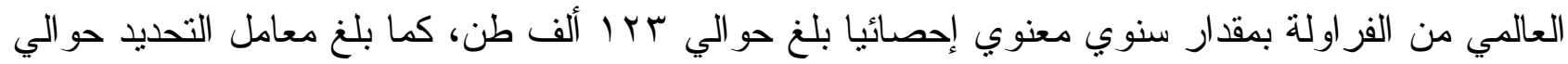

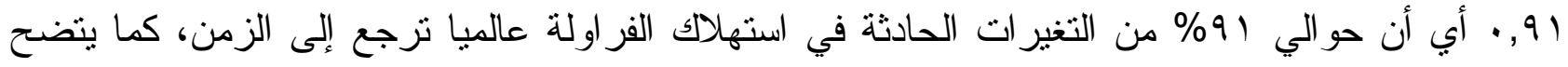

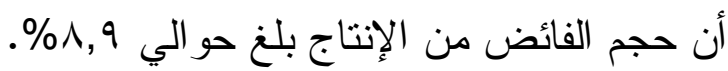

جدول (Y) الإنتاج والاستهلاك العالمي بالألف طن ومتوسط نصيب الفرد بالكجم/ سنه من الفراولة

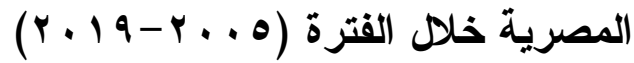

\begin{tabular}{|c|c|c|c|c|c|}
\hline لنصيب الثرقي القياسي & متوسط نصيب & نسبة الاستتهلاك & الاستثلاككي & الإتتاج العالمي & السنوات \\
\hline 97.4 & 0.43 & 79.03 & 2457 & 2362 & 2005 \\
\hline 99.2 & 0.43 & 80.31 & 2469 & 2516 & 2006 \\
\hline 102.4 & 0.44 & 82.55 & 2570 & 2671 & 2007 \\
\hline 109.3 & 0.48 & 77.18 & 2874 & 2825 & 2008 \\
\hline 102.7 & 0.50 & 84.42 & 3500 & 2979 & 2009 \\
\hline 96.7 & 0.48 & 87.57 & 2929 & 3133 & 2010 \\
\hline 99.8 & 0.48 & 87.99 & 2918 & 3288 & 2011 \\
\hline 100.7 & 0.48 & 88.62 & 3519 & 3349 & 2012 \\
\hline 109.4 & 0.53 & 89.23 & 3375 & 3651 & 2013 \\
\hline 102.6 & 0.54 & 90.58 & 3476 & 3779 & 2014 \\
\hline 104.2 & 0.57 & 87.84 & 3678 & 3973 & 2015 \\
\hline 100.2 & 0.57 & 85.51 & 3729 & 4002 & 2016 \\
\hline 100.3 & 0.58 & 89.71 & 3829 & 4137 & 2017 \\
\hline 108.8 & 0.63 & 87.78 & 4246 & 4597 & 2018 \\
\hline 93.7 & 0.59 & 87.59 & 4004 & 4367 & 2019 \\
\hline 102.3 & 0.51 & 92.17 & 3194 & 3442 & |المتوسط \\
\hline
\end{tabular}

source: www.faostat.org

ب- تطور متوسط نصيب الفرد من استهلاك الفر اولة عالميا:

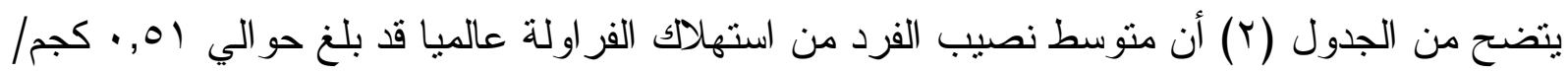

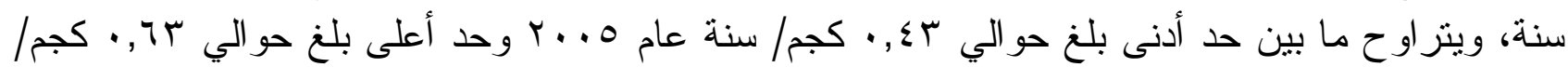

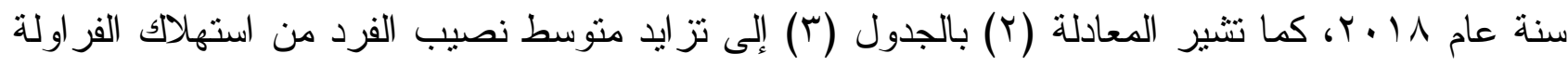

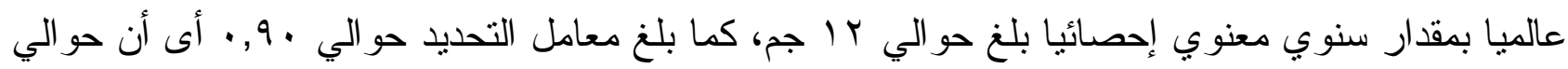

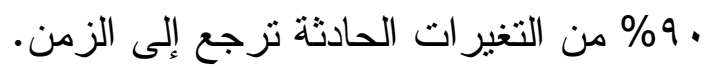
ع - تطور الاستهلاك المحلي من القراولة:

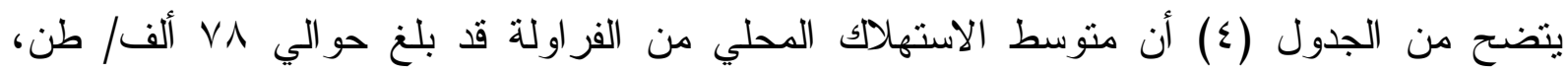

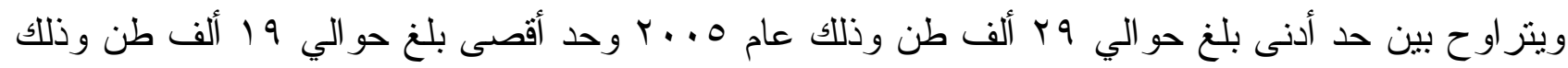

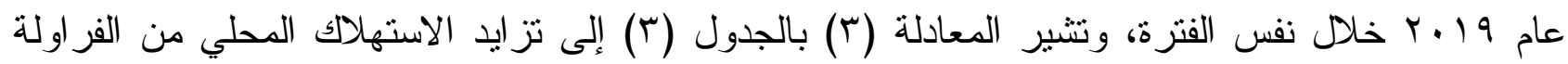

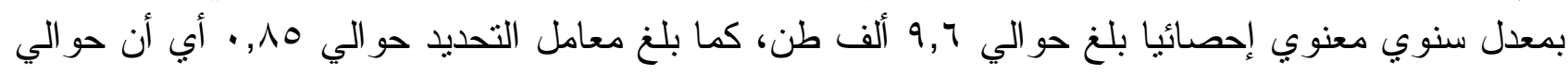

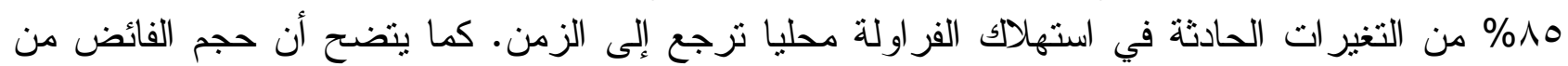

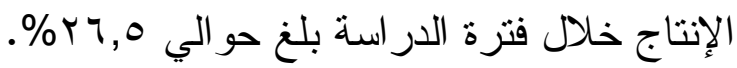




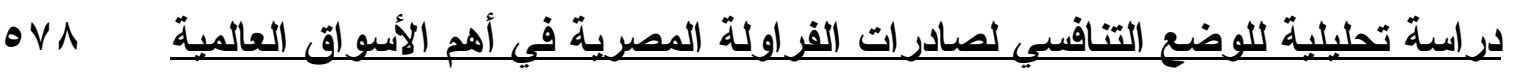
جدول (ب) معادلات الاتجاه الزمني العام لتطور كل من الاستهلاك العالمي والمحلى من الفراولة

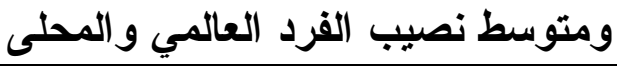

\begin{tabular}{|c|c|c|c|c|}
\hline $\mathbf{F}$ & $\mathbf{R}^{2}$ & المعادلة & البيان & p \\
\hline 630 & 0.98 & $\begin{array}{c}\hat{Y_{i}}=2467+123 X_{i} \hat{Y}=2208+154 \mathrm{x} \\
(38.2) * * \quad(25.1)^{* *}\end{array}$ & الإنتاج العالمي & 1 \\
\hline 282 & 0.91 & $\begin{array}{c}Y_{i}=2467+123 X_{i} \\
(35.0)^{* *} \quad(16.8)^{* *}\end{array}$ & الاستهلاك العالمي ألف طن & 2 \\
\hline 154 & 0.90 & $\begin{array}{c}Y_{i}=2467+123 X_{i} Y_{i}=0.40+0.012 X_{i} \\
(37.7)^{* *}(12.4)^{* *}\end{array}$ & متوسط نصيب الفرد (العالمي) كجم/ سنة & 3 \\
\hline 83 & 0.85 & $\begin{array}{l}Y_{i}=3.2+9.6 X_{i} \\
\quad(0.3) \quad(9.1)^{* *}\end{array}$ & الاستهلاك القومي (ألف طن) & 4 \\
\hline 79 & 0.85 & $\begin{array}{l}\hat{Y}_{i}=0.09+0.10 X_{i} \\
\quad(0.7) \quad(8.9)^{* *}\end{array}$ & متوسط نصيب الفرد (المحلي) كجم/ سنة & 5 \\
\hline
\end{tabular}

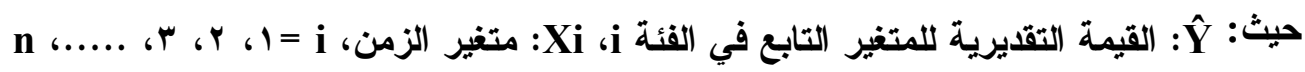

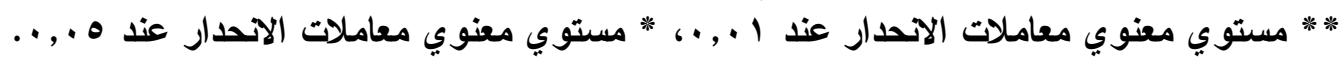

المصدر: حسبت من الجدول (r).

جدول ( ؛) الإنتاج والاستهلاك القومي بالألف طن ومتوسط نصيب الفرد من بالكجم/ سنة من محصول

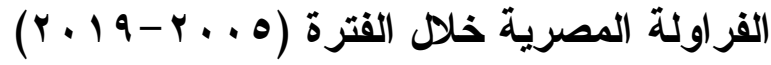

\begin{tabular}{|c|c|c|c|c|c|}
\hline لالرقيب القياسيدي & متوسط نصيب & نسبة الاستتهلاك & الاستهلاكي & ألف طالْن & السنوات \\
\hline 114.7 & 0.45 & 79.07 & 29 & 37 & 2005 \\
\hline 122.7 & 0.54 & 78.91 & 36 & 46 & 2006 \\
\hline 112.7 & 0.61 & 78.88 & 41 & 52 & 2007 \\
\hline 100.5 & 0.61 & 78.72 & 42 & 54 & 2008 \\
\hline 135.5 & 0.80 & 79.61 & 56 & 71 & 2009 \\
\hline 93.4 & 0.74 & 78.54 & 54 & 68 & 2010 \\
\hline 84.7 & 0.63 & 76.97 & 46 & 60 & 2011 \\
\hline 135.7 & 0.82 & 77.16 & 62 & 80 & 2012 \\
\hline 129.5 & 2.07 & 77.37 & 81 & 105 & 2013 \\
\hline 93.7 & 2.00 & 77.55 & 78 & 100 & 2014 \\
\hline 117.1 & 2.17 & 72.09 & 93 & 128 & 2015 \\
\hline 129.7 & 2.52 & 70.08 & 122 & 174 & 2016 \\
\hline 123.1 & 2.88 & 76.29 & 153 & 200 & 2017 \\
\hline 92.2 & 2.71 & 57.92 & 141 & 243 & 2018 \\
\hline 134.5 & 2.35 & 80.00 & 191 & 238 & 2019 \\
\hline 113 & 2.02 & 73.58 & 78 & 106 & المتوسط \\
\hline
\end{tabular}

المصدر: الجهاز المركزي للتعبئة العامة والإحصاء، نشرة الميزان الغذائي، أعداد مختلفة.

ه - تطور متوسط نصيب الفرد من الاستهلاك القومي الفراولة:

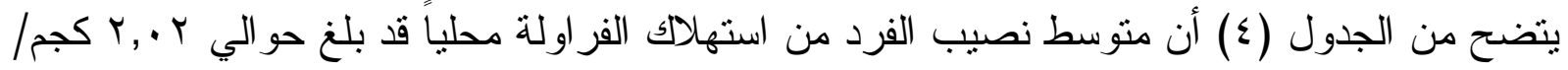

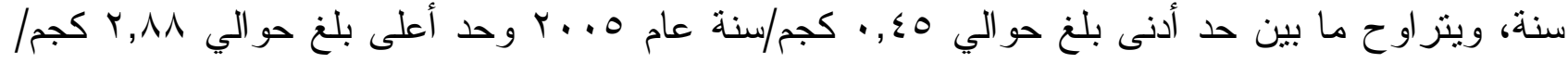

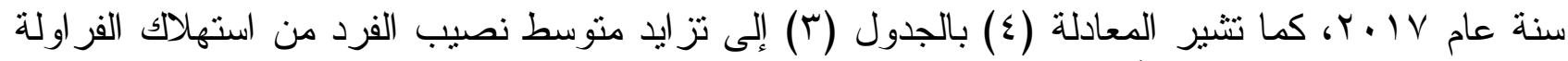

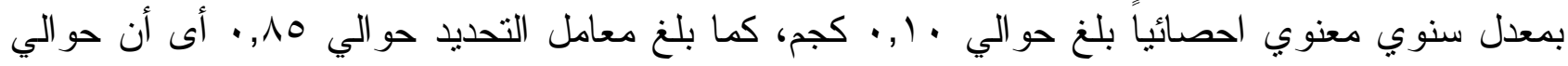

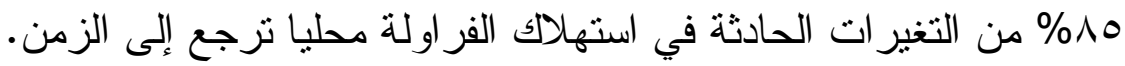




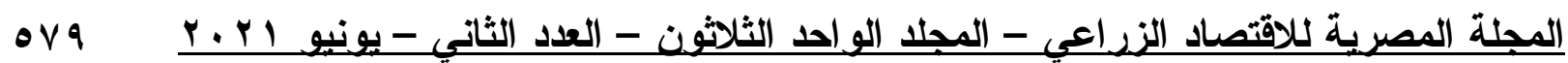

أ-تطور الطاقة التصديرية لمحصول الفراولة المصرية:

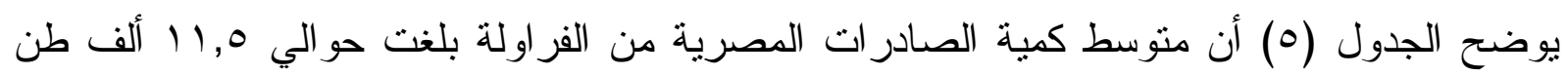

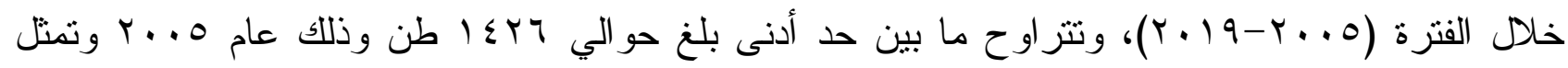

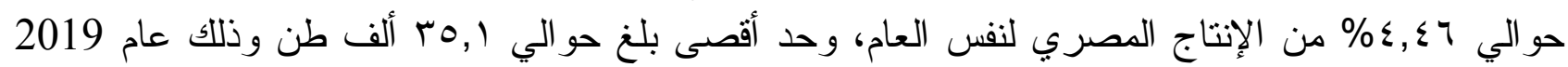

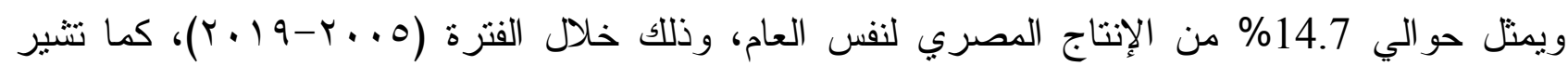
المعادلة (1) بالجدول (7) إلى تز ايد كمية الصادر ات المصرية من محصول الفراولة بمقدار سنوي معنوي

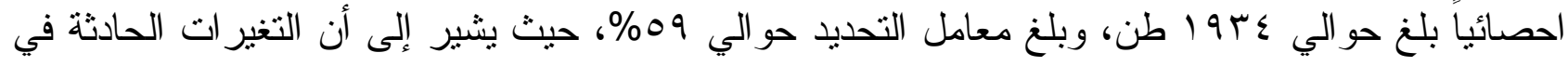

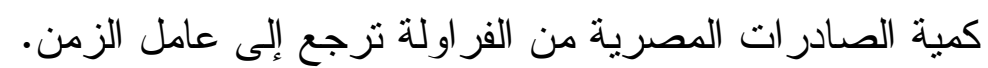

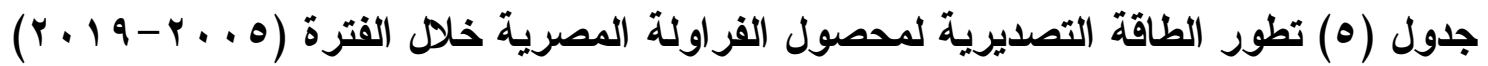

\begin{tabular}{|c|c|c|c|c|}
\hline \multirow{2}{*}{ \% الصادر ات من } & \multicolumn{3}{|c|}{ الصادر ات } & \multirow{2}{*}{ السنوات } \\
\hline & السعر ألف دولار/ طن & القيمةٌ بالآلف دولار & الكميةٌ بالطن & \\
\hline 4.46 & 478 & 1067 & 1426 & 2005 \\
\hline 5.28 & 418 & 1014 & 2426 & 2006 \\
\hline 6.88 & 443 & 1595 & 3600 & 2007 \\
\hline 12.53 & 428 & 2879 & 6727 & 2008 \\
\hline 12.54 & 391 & 3462 & 8854 & 2009 \\
\hline 9.35 & 346 & 2193 & 6338 & 2010 \\
\hline 13.73 & 257 & 2118 & 8240 & 2011 \\
\hline 9.11 & 393 & 2857 & 7270 & 2012 \\
\hline 9.36 & 520 & 5108 & 9823 & 2013 \\
\hline 5.12 & 965 & 4940 & 5119 & 2014 \\
\hline 4.76 & 910 & 5557 & 6107 & 2015 \\
\hline 4.56 & 915 & 7272 & 7947 & 2016 \\
\hline 17.05 & 1057 & 8255 & 34149 & 2017 \\
\hline 12.79 & 1547 & 9420 & 28616 & 2018 \\
\hline 14.73 & 1538 & 10586 & 35119 & 2019 \\
\hline 9.48 & 725 & 4555 & 11451 & المتوسط \\
\hline
\end{tabular}

\section{Source: www.faostat.org}

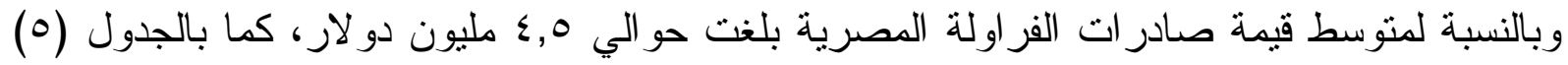

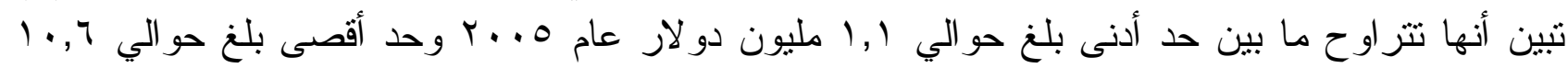

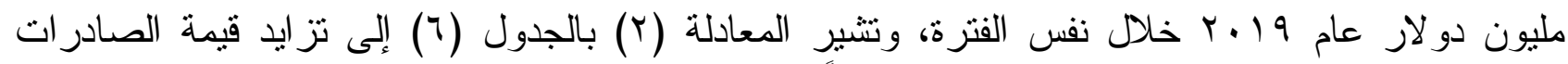

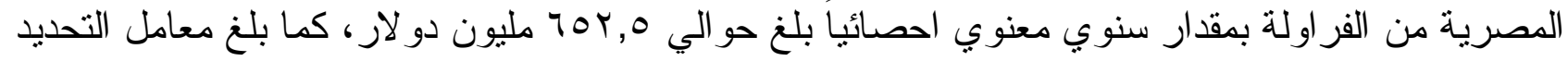

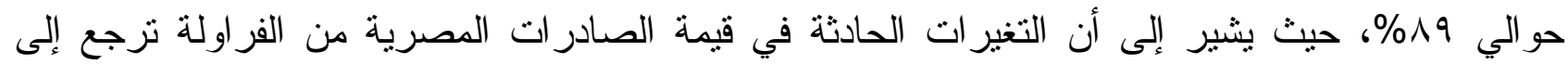
عامل الزمن.

جذول ( ا) معادلات الاتجاه الزمني العام لتطور كمية وقيمة وسعر صادرات محصول الفراولة المصرية

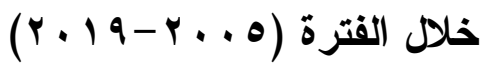

\begin{tabular}{|c|c|c|c|c|}
\hline $\mathbf{F}$ & $\mathbf{R} 2$ & المعادلة & البيان البيان & b \\
\hline 18.5 & 0.59 & $\begin{array}{c}\hat{\mathrm{Y}}=-4021+1934 \mathrm{X} \\
(-1.0) \quad(4.3)^{* *}\end{array}$ & كمية صادرات الفراولة بالطن & 1 \\
\hline 17.6 & 0.89 & $\begin{array}{cc}- & -665.6+652.5 \mathrm{x} \\
(-1.1) & (10.1)^{* *}\end{array}$ & قيمة صادرات الفراولة بالألف دولار & r \\
\hline 25.0 & 0.60 & $\begin{array}{c}\mathrm{Y}=142.8+72.8 \mathrm{x} \\
(1.0) \quad(4.4)^{* *}\end{array}$ & سعر صادرات الفراولة بالدولار & $r$ \\
\hline
\end{tabular}

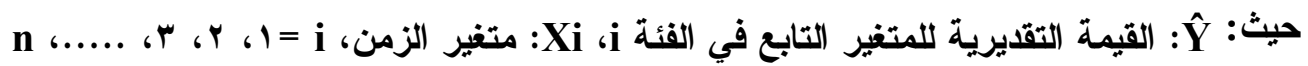

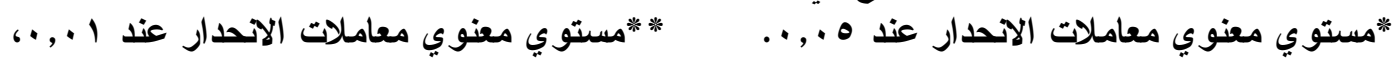

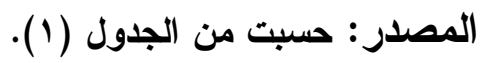




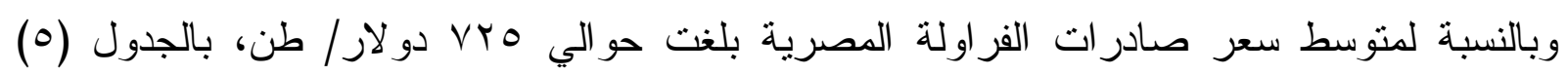

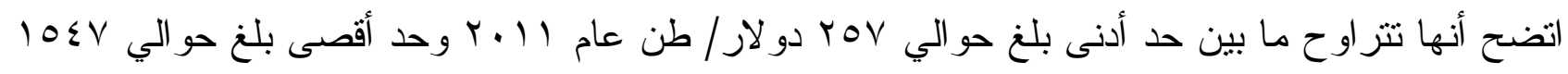

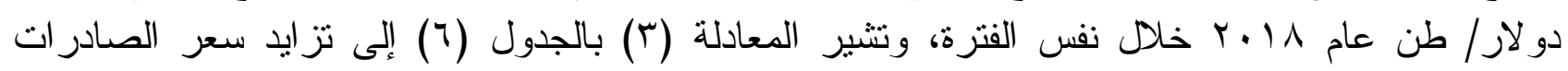

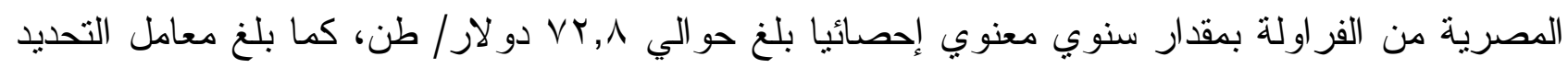

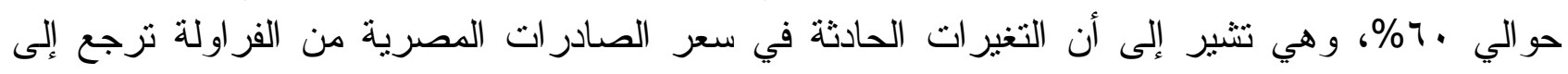
عنصر الزمن.

ج- التوزيع الجغرافي لصادرات مصر من محصول الفراولة:

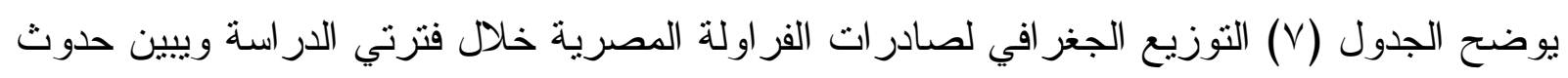

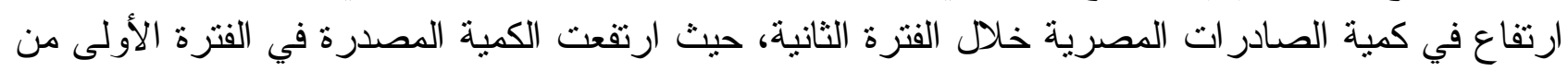

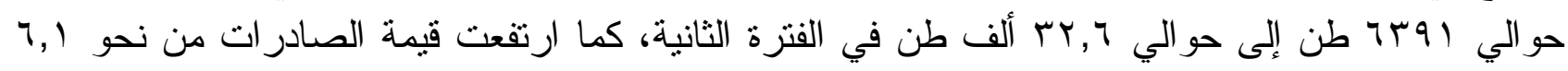
مليون دو لار خلال الفترة الأولى إلى حوالي ^رئى عـ مليون دو لار في الفترة الثانية.

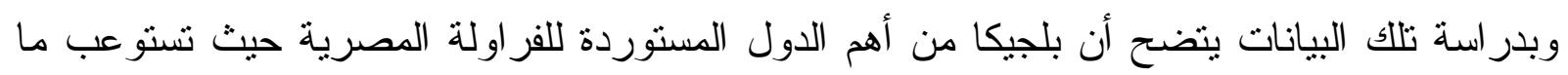

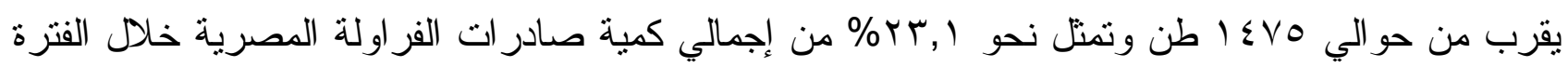

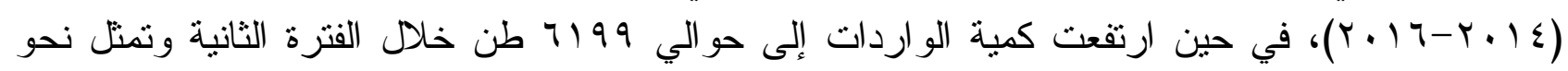
9 1\% من إجمالي كمية صادر ات الفر اولة المصرية.

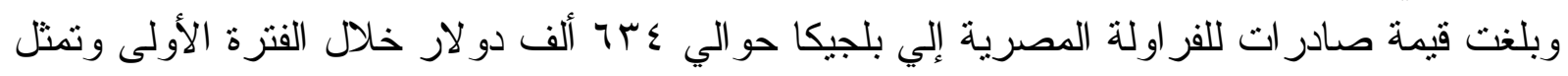
نحو 0, • 1\% من متوسط إجمالي قيمة صادر ات الفراولة المصرية، وبلغت قيمة صادر ات الفر اولة المصرية

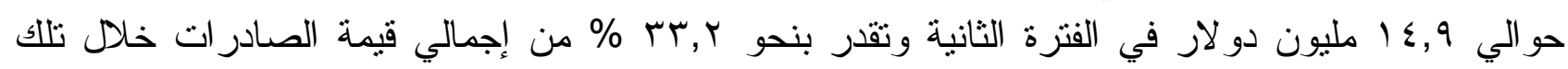

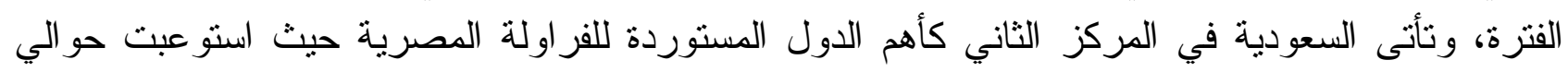

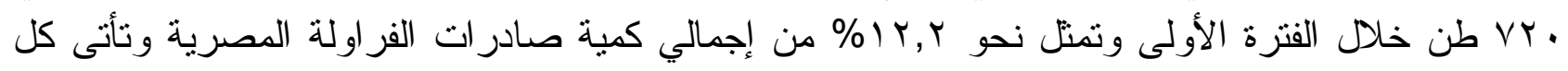

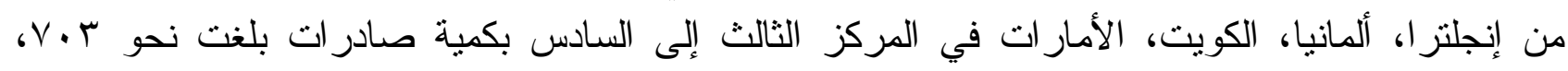

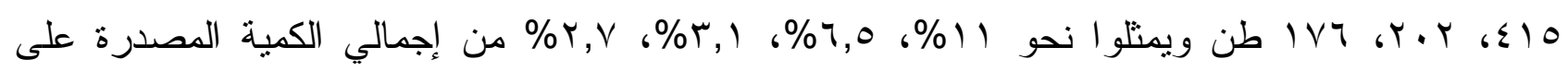

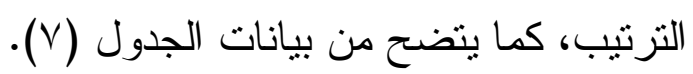

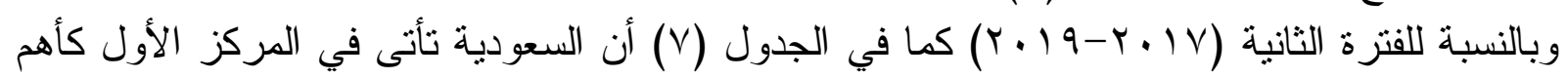

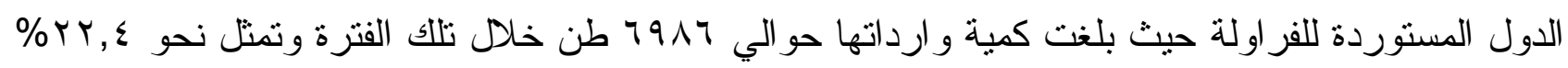
من متوسط صادرات الفراولة المصرية، وتأتى كل من إنجلتر ا، ألمانيا، الأمار ات في المر اكز الثالث إلى إنى

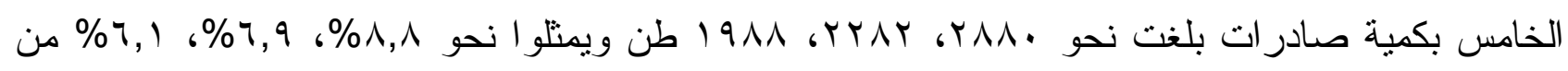

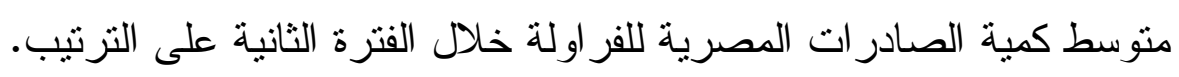

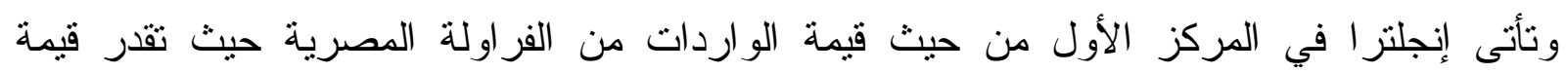

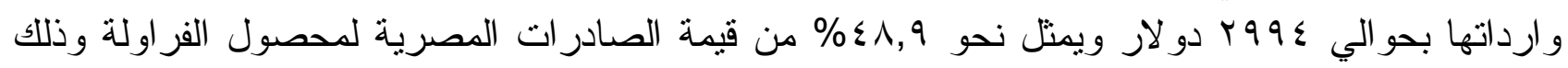

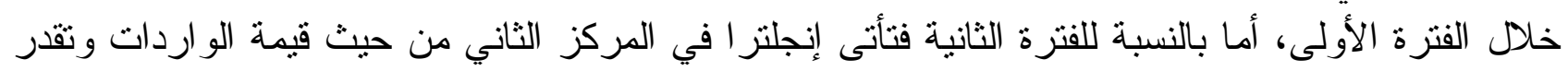

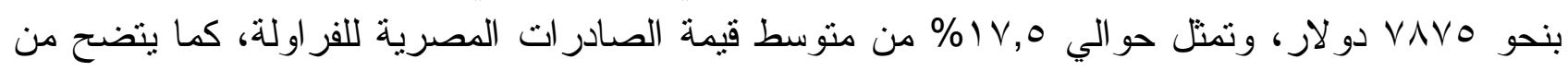

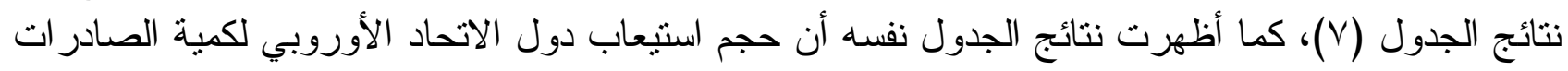

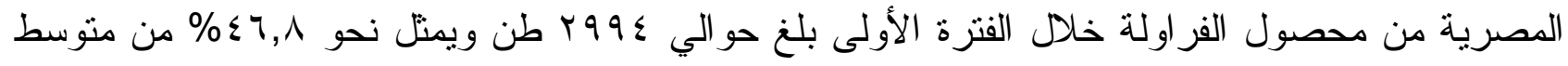

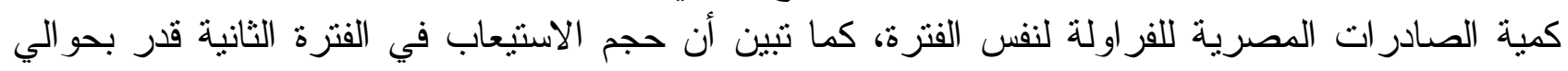

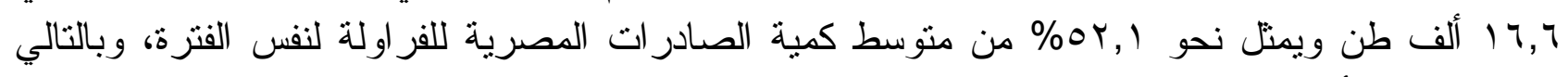
تعتبر السوق الأوروبية السوق الرئيسية للصادر ات المصرية من من الفر اولة. 


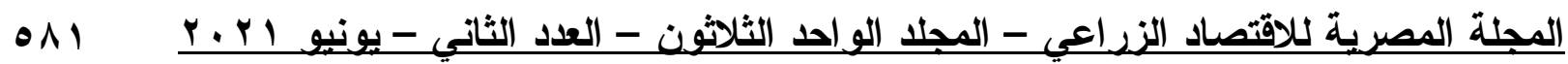

جدول (V) التوزيع الجغرافي لصادرات الفراولة المصرية وفقاً للأهمية النسبية خلا فترتي الدراسة

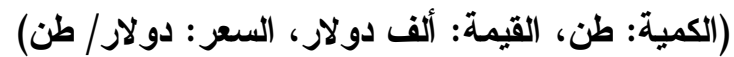

\begin{tabular}{|c|c|c|c|c|c|c|c|c|c|c|}
\hline \multicolumn{5}{|c|}{ 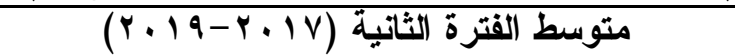 } & \multicolumn{5}{|c|}{ 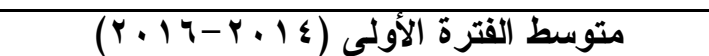 } & \multirow{2}{*}{ 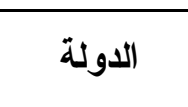 } \\
\hline سعر & $\%$ & قيمة & $\%$ & كمية & سعر & $\%$ & قيمة & $\%$ & كمية & \\
\hline 2404 & 33.27 & 14901 & 19.00 & 6199 & 436 & 10.52 & 643 & 23.08 & 1475 & بلجيكا \\
\hline 1859 & 9.47 & 4243 & 6.99 & 2282 & 2947 & 20.01 & 1223 & 6.49 & 415 & ألمانيا \\
\hline 2734 & 17.58 & 7875 & 8.94 & 2880 & 4259 & 48.99 & 2994 & 12.00 & 703 & إنجلترا \\
\hline 1112 & 4.08 & 1827 & 5.04 & 1643 & 653 & 2.33 & 81 & 2.94 & 124 & هولندا \\
\hline 815 & 6.67 & 2988 & 12.23 & 3665 & 426 & 2.93 & 118 & 4.33 & 277 & \\
\hline 1910 & 72.1 & 31944 & 52.09 & 16669 & 1690 & 82.8 & 5059 & 46.85 & 2994 & إلأجمالي الاولة \\
\hline 699 & 10.91 & 4886 & 22.41 & 6986 & 469 & 5.53 & 338 & 12.27 & 720 & السعودية \\
\hline 985 & 4.37 & 1919 & 6.09 & 1988 & 415 & 2.19 & 73 & 2.75 & 176 & الأمار ات \\
\hline 1177 & 4.45 & 1993 & 5.19 & 1694 & 490 & 2.62 & 99 & 3.16 & 202 & الكويت \\
\hline 793 & 0.78 & 349 & 2.35 & 440 & 397 & 0.41 & 25 & 0.99 & 63 & البحرين \\
\hline 692 & 0.67 & 351 & 2.33 & 435 & 700 & 0.11 & 7 & 0.16 & 10 & الأردنن \\
\hline 774 & 0.62 & 277 & 2.10 & 358 & 599 & 2.94 & 112 & 2.93 & 187 & قطر \\
\hline 485 & 2.20 & 538 & 3.40 & 1109 & 370 & 0.42 & 25 & 2.07 & 68.6 & باقي الاولة \\
\hline 792 & 23.0 & 10353 & 39.87 & 13510 & 3440 & 12.12 & 679 & 22.32 & 1427 & إجمالي الدولية \\
\hline 1373 & 2.46 & 652 & 2.46 & 475 & 1250 & 0.16 & 10 & 0.13 & 8 & روسبيا \\
\hline 949 & 4.50 & 2015 & 7.36 & 2403 & 185 & 5.94 & 363 & 35.67 & 1960 & باقي العالم \\
\hline 1373 & 100 & 44792 & 100 & 32629 & 916 & 100 & 6111 & 100 & 6391 & الإجمالي \\
\hline
\end{tabular}

Source: www.faostat.org

في حين أظهرت النتائج الموضحة بالجدول (V) زيادة متوسط سعر تصدير الطن من الفراولة المصرية خلال الفترة الثانية، حيث بلغ خلال الفنرة الأولى نحو 7 اوه دولار/ طن وبلغ في الفترة الثانية

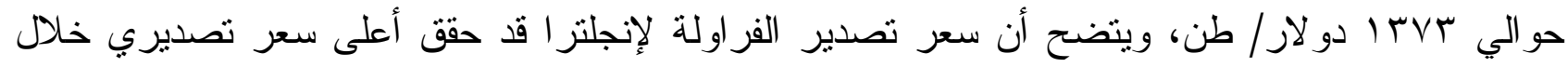

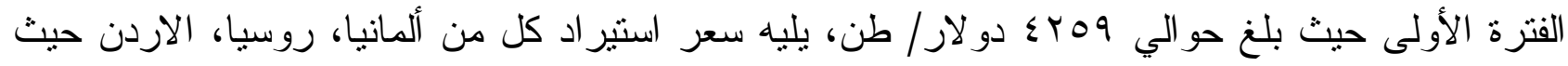

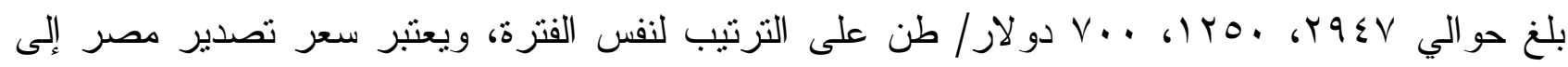

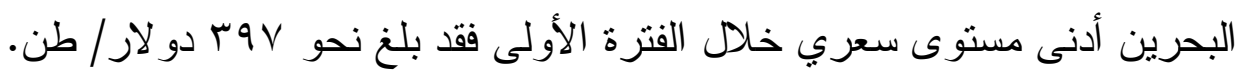

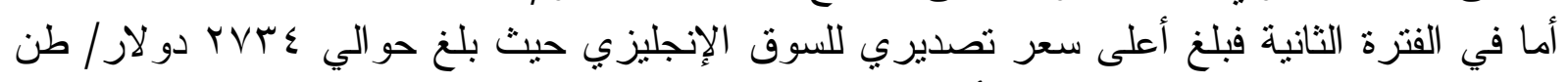

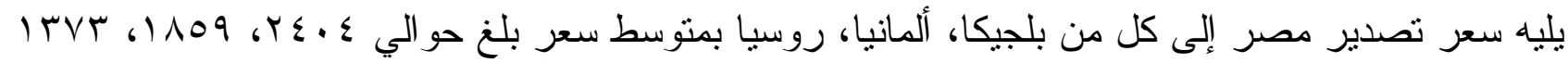

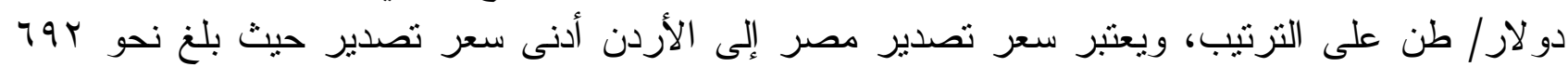

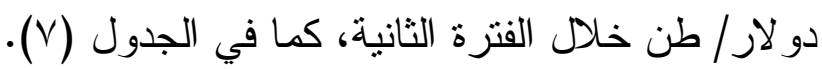
وبوجه عام فقد ارتفعت الكمية المصدرة من الفراولة المصرية داخل الأسواق العالمية خلال الفترة التانية عن الأولي، كذلك أرتفع السعر التصديري لمصر في معظم الدول باستثناء ألمانيا و إنجلتر او الأردن فقد الأدة انخفض للفترة الثانية عن الفترة الأولي. ثانياً: الأوضاع التنافسية لمحصول الفراولة المصرية في أهم الأسواق الاستيرادية:

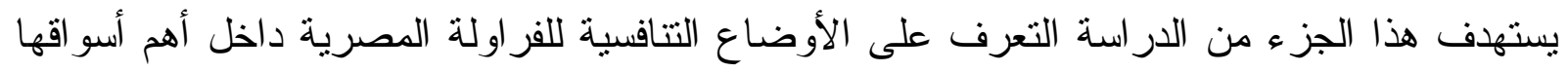

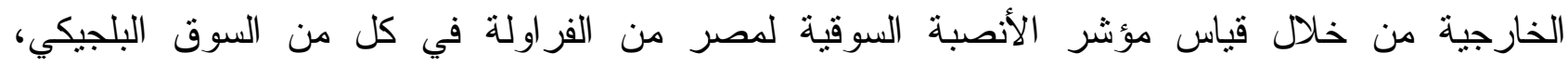
و السعودي، الإنجليزي والألماني، حيث تعنبر هذه الأسواق من أهم الأسواق المستوردة للفراولة المصرية 
در داسة تحليلية للوضع التنافسي لصادرات الفراولة المصرية في أهم الأسواق العالمبة

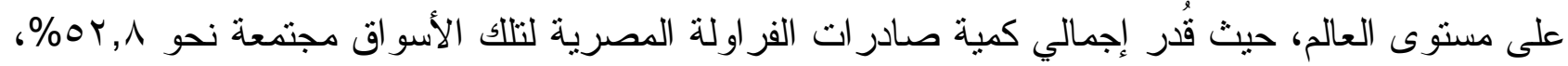

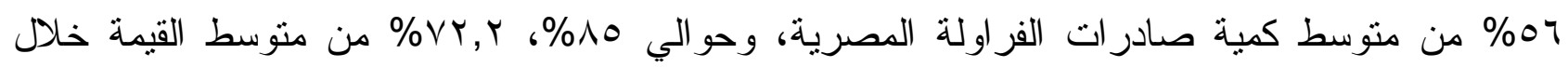
فتزتي الدر اسة.

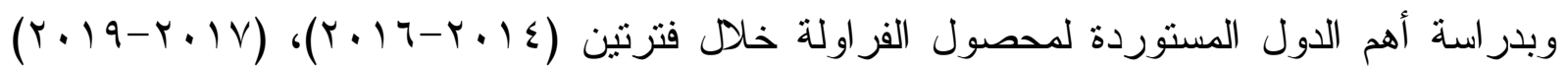
ومن هذا المنطلق سيتم در اسة كل سوق من هذه الأسواق لكل محصول لتحديد أهم المنافسين لمصر وكذلك

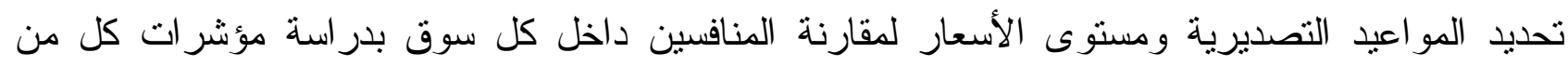

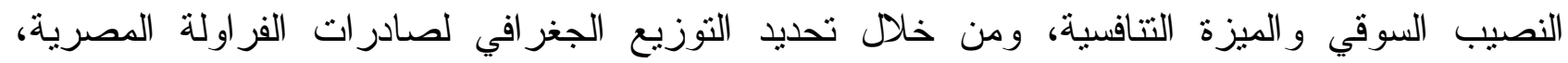
و الموضح بالجدول (V) تنين أن أهم الدول المستوردة هي بلجيكا، ألمانيا، السعودية، إنجلتز ا وتمثل نحو

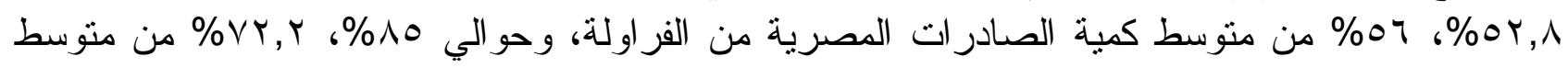
القيمة خلال فترتي الدر اسة، وبالإشارة لهذه النسب سيتم در اسة التة هذه الأسو اق. 1) (السوق البلجيكية:

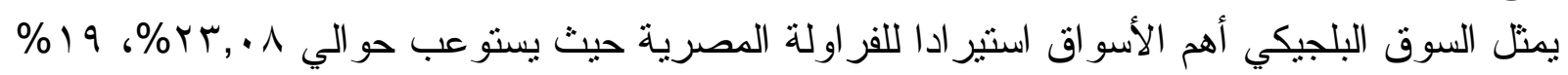

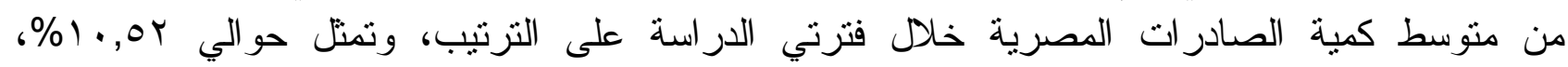

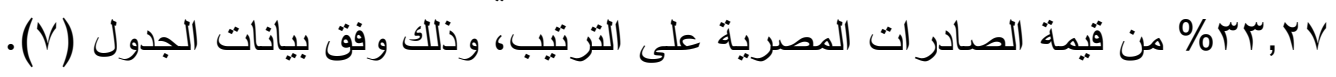
أ- الأنصبة السوقية لأهم الدول المنافسة لمصر الهر داخل السوق البلجيكي:

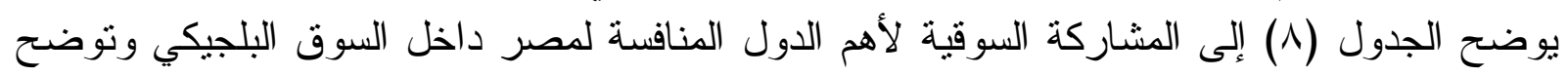
البيانات انخفاض الكمية المستوردة خلال الفترة الأولى من حوالي 9 ,ــ ألف طن إلى نحو

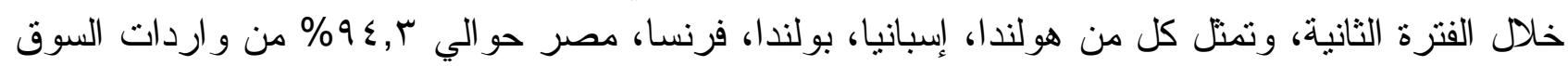

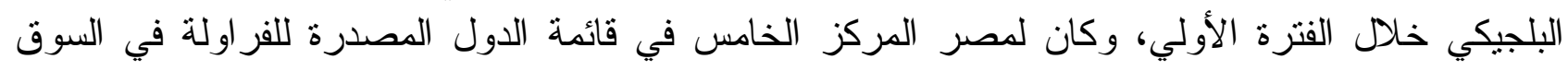
البلجيكي خلال الفترة الأولى بكمية صادر ات قدرت بنحو

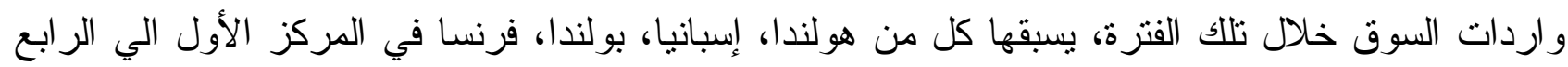

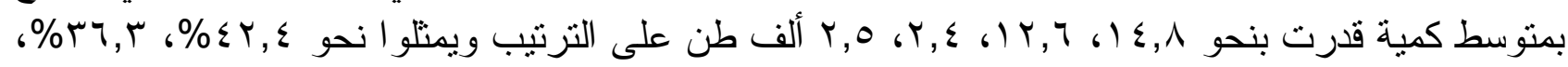

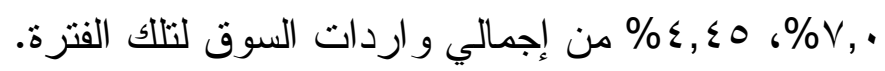

جول (^) النصيب السوقي لأهم الاول المنافسة لصادرات مصر من الفراولة للسوق البلجيكي

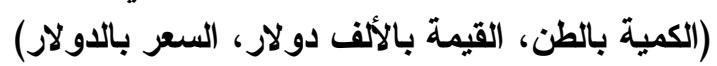

\begin{tabular}{|c|c|c|c|c|c|c|c|c|c|c|c|c|}
\hline \multirow[b]{2}{*}{ السمو } & \multirow[b]{2}{*}{ نمول } & \multicolumn{5}{|c|}{ 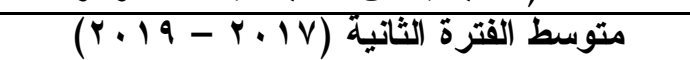 } & \multicolumn{5}{|c|}{ 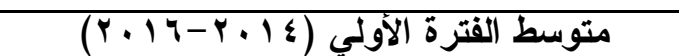 } & \multirow[b]{2}{*}{ 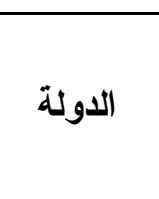 } \\
\hline & & الستافيزية & 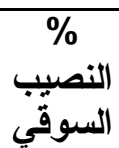 & 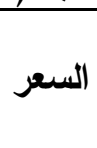 & 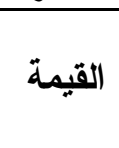 & 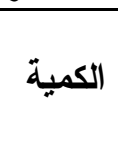 & التنافيزية & $\begin{array}{c}\% \\
\text { السوقيب }\end{array}$ & 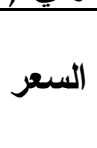 & 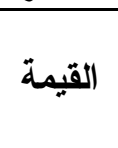 & 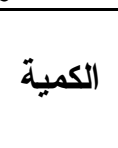 & \\
\hline 450 & 320 & 2.00 & 22.69 & 2400 & 14901 & 6199 & 2.00 & 4.22 & 436 & 643 & 1475 & مصر \\
\hline 0 & 62 & 0.99 & 0.07 & 2380 & 50 & 21 & 5.47 & 0.04 & 2385 & 31 & 13 & أثيوبيا \\
\hline 31 & -46 & 2.46 & 2.91 & 3500 & 2915 & 942 & 6.14 & 4.45 & 2678 & 4164 & 1555 & فرنسا \\
\hline 84 & -29 & 0.87 & 0.65 & 2080 & 389 & 187 & 2.60 & 0.76 & 1132 & 350 & 265 & ألماتيا \\
\hline-9 & $\begin{array}{l}-50 \\
\end{array}$ & 2.89 & 2.92 & 4535 & 2488 & 549 & 12.38 & 3.13 & 4961 & 5422 & 1093 & إسر ائيل \\
\hline 67 & 61 & 0.81 & 0.23 & 1910 & 129 & 66 & 2.69 & 0.12 & 1171 & 48 & 41 & إيطاليا \\
\hline 78 & -67 & 0.98 & 0.05 & 2360 & 33 & 14 & 3.04 & 0.12 & 1326 & 57 & 43 & المغرب \\
\hline 127 & -35 & 2.76 & 36.11 & 4235 & 43611 & 10320 & 4.27 & 42.39 & 1863 & 27604 & 14817 & هولتندا \\
\hline 76 & -3 & 0.42 & 8.31 & 1020 & 2422 & 2375 & 2.33 & 7.02 & 579 & 1422 & 2454 & بولندا \\
\hline 94 & -47 & 2.31 & 23.66 & 3160 & 21358 & 6761 & 3.73 & 36.27 & 1628 & 20635 & 12677 & إسبانيا \\
\hline 52 & -47 & 0.45 & 0.90 & 1070 & 375 & 357 & 2.61 & 2.39 & 702 & 341 & 486 & إنجلترا \\
\hline-56 & 2667 & 0.49 & 3.49 & 1180 & 1175 & 996 & 6.12 & 0.10 & 2667 & 96 & 36 & دول العالم \\
\hline 81 & -18 & 2.31 & 100 & 3140 & 89476 & 28577 & 3.99 & 100 & 1738 & 60763 & 34915 & الإجمالي \\
\hline
\end{tabular}




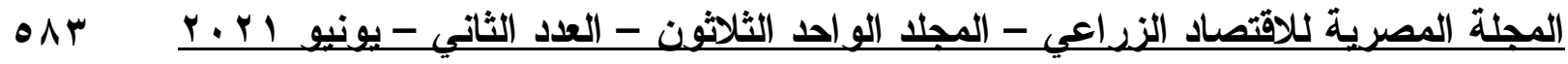

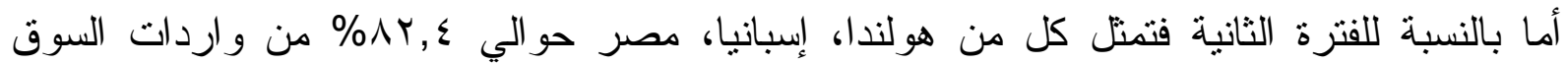
البلجيكي، كما بالجدول (^)، وكان لمصر المركز الثالث كأهم الدول المصدرة لمحصول الفرانيا، اولة في السوق

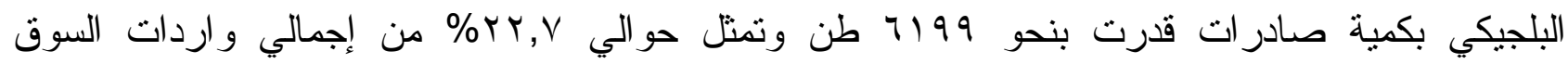
البلجيكي لنفس الفترة تسبقها كل من هولندا، إسبانيا في المركز الأول و الثاني على الترتيب بمتوسط كمية

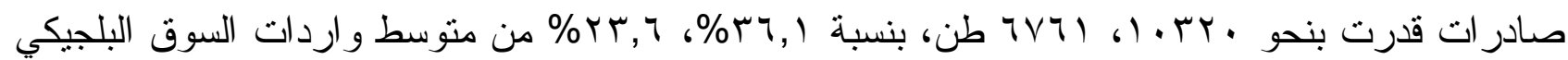
لنفس الفترة على التزتيب، كما تبين أن أعلى معدل نمو للكمية المستوردة من الفر اولة داخل السوق البلجيكي

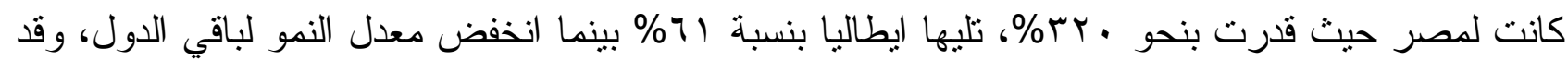

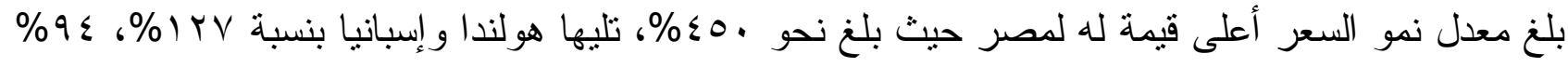
على الترتيب وذللك خلال نفس الفترة، وبالرغم من ارتفاع معدل نمو السعر إلا أن السعر التصديري لمصر

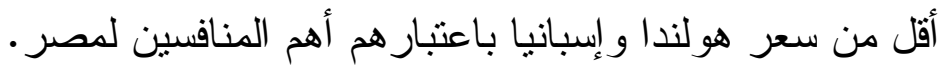

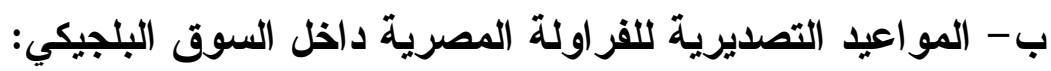
يعتبر موسم التصدير الخاص بالفراولة داخل السوق البلجيكي هي الفترة من اكتوبر الي مايو وذللك

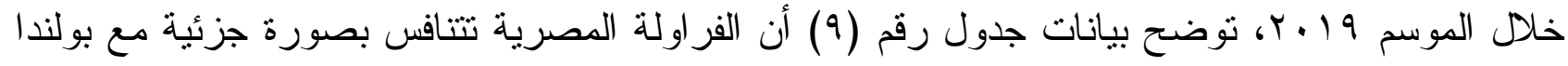

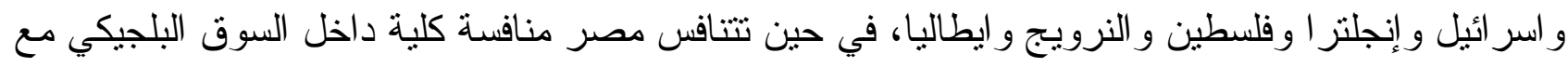

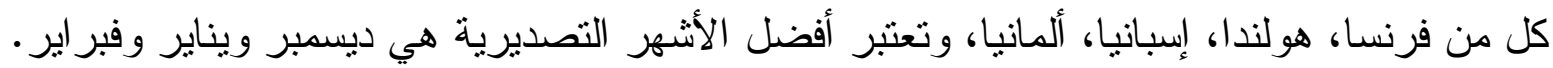

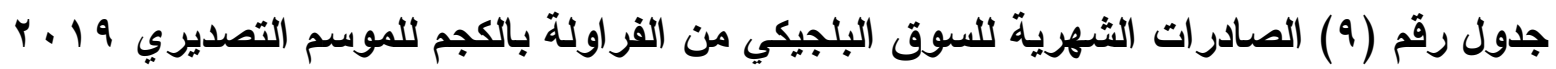

\begin{tabular}{|c|c|c|c|c|c|c|c|c|c|c|c|c|}
\hline Dec & Nov & Oct & Sep & Aug & Jul & Jun & May & Apr & Mar & Feb & Jan & اللدولة \\
\hline 4891 & 4641 & 9177 & 11151 & 22416 & 25164 & 24959 & 23457 & 10060 & 1823 & 754 & 963 & هولندا \\
\hline 331 & & 5 & & & 8162 & 9804 & 12487 & 24098 & 19655 & 5848 & 485 & إسباتيا \\
\hline \multirow[t]{2}{*}{5683} & 66 & 35 & & & & & 10 & 21 & 207 & 5159 & 6004 & مصر \\
\hline & & & & & 53 & 7204 & & & & & & بولندا \\
\hline 114 & 15 & 75 & 35 & 15 & 55 & 369 & 489 & 2796 & 1993 & 359 & 153 & فرنسا \\
\hline 286 & & & & & & & & & 921 & 1492 & 1791 & إسر ائيل \\
\hline 22 & 0 & 15 & 4 & 72 & 366 & 536 & 100 & 933 & 637 & 93 & 10 & آلماتيا \\
\hline 698 & & & & & & & & & 485 & 185 & 974 & فُلسطين \\
\hline 122 & & & & & & & & 18 & 73 & 112 & 140 & اثيوبيا \\
\hline \multirow[t]{6}{*}{10} & 12 & 6 & 6 & 10 & 0 & & & & 78 & 83 & 22 & إنجلتر ا \\
\hline & & 14 & 16 & & & & 196 & & & & & اللرويج \\
\hline & & & & & & 6 & & 24 & 13 & 50 & 29 & إيطاليا \\
\hline & & & & & & & 73 & & & & & إستونيا \\
\hline & 35 & & & & & 28 & & & & 8 & 1 & التشيك \\
\hline & & & 24 & & 18 & & 30 & & & & & السويد \\
\hline
\end{tabular}

المصدر: الهيئة العامة للرقابة على الصادرات و الواردات، قطاع التجارة الخارجية.

ج- المنافسة السعرية داخل السوق البلجيكي: ويوضح جدول (^) منوسط أسعار تصدير أهم الدول في السوق البلجيكي لمحصول الفراولة، حيث

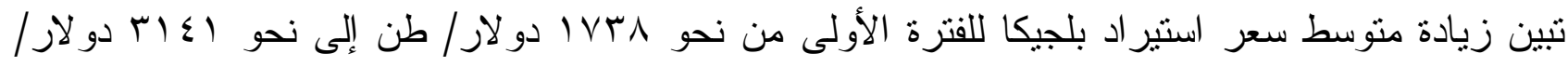

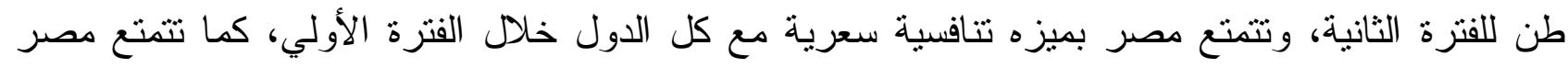

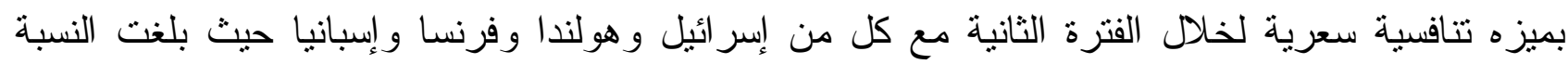

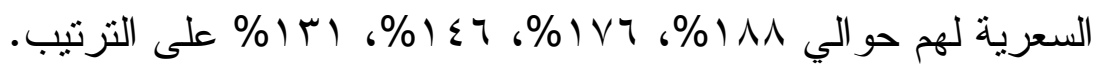




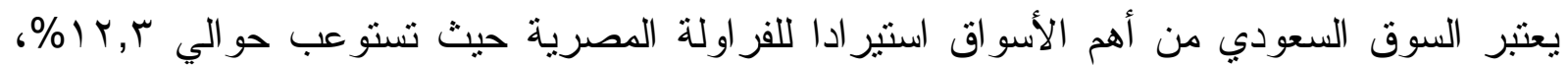

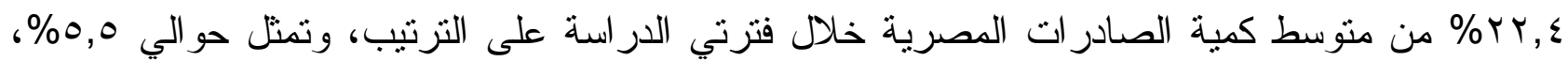
9, • ( \% من قيمة الصادر ات المصرية على الترتيب لنفس الفترتين وذلك وفق بيانات الجدول (V). أـ الأنصبة السوقية لأهم الاول المنافسة لمصر داخل السوق السعودي:

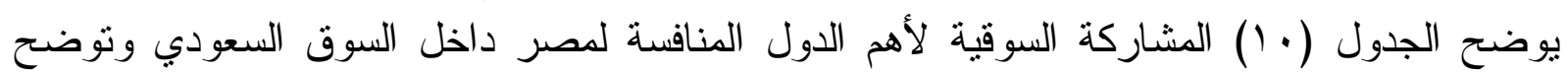

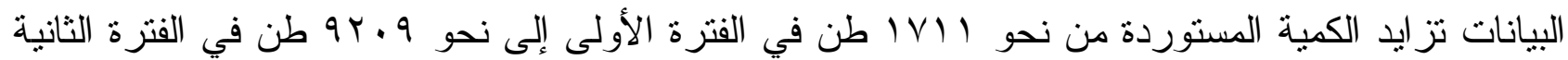

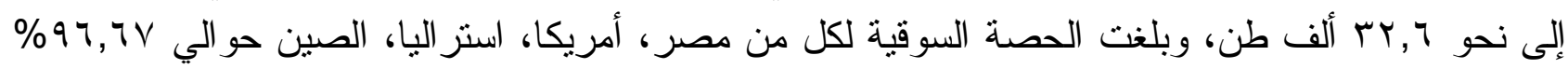
من إجمالي واردات السوق السعودي خلال الفترة الأولي، وكان لمصر المركز الأول في قائمة الدول

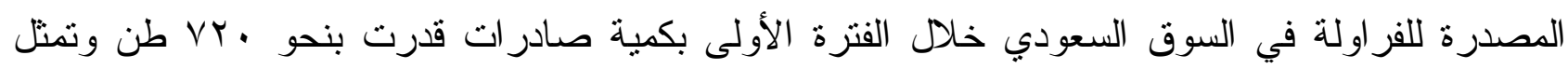

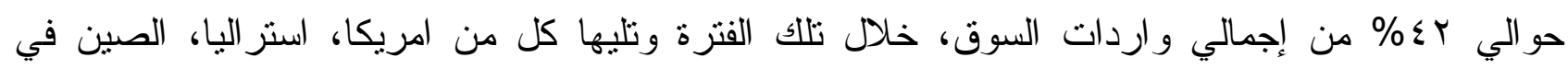

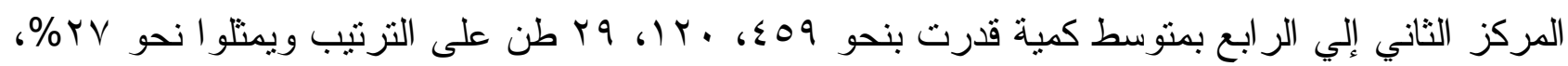
\% \% r r \% من إجمالي و اردات السوق السعودي لتلك الفترة. أما بالنسبة للفترة الثانية فقد بلغت الحصة السوقية لكل من مصر، امريكا، تونس، استر اليا حوالي 99 9 من إجمالي واردات السوق السعودي فكان لمصر المركز الأول، كما هو موضح بالجدول ( • ( ) كأهم

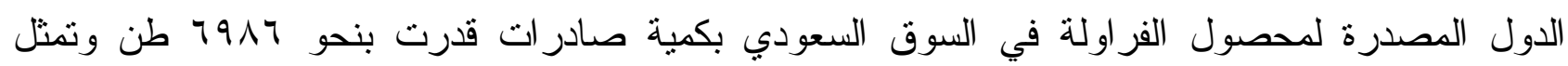

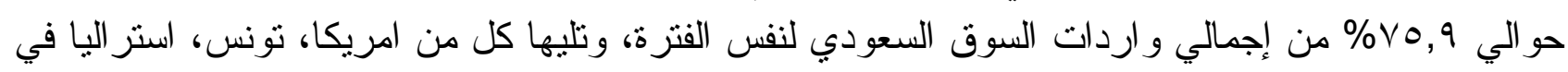

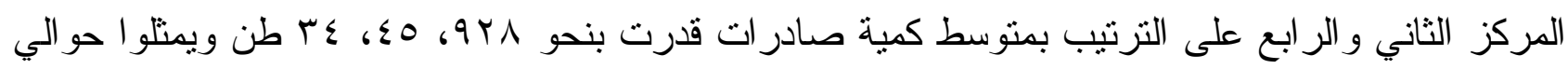

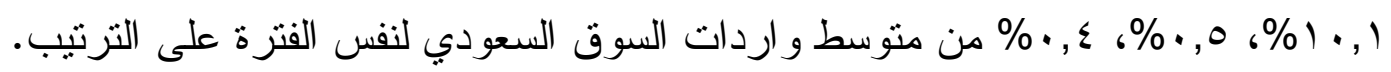

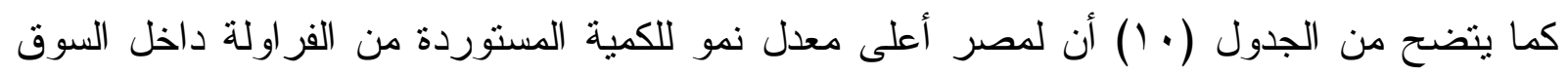

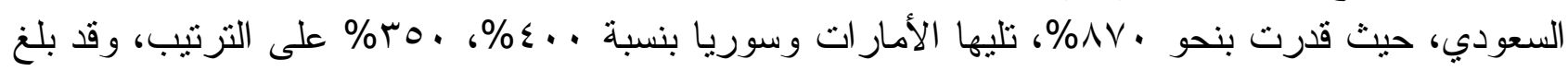

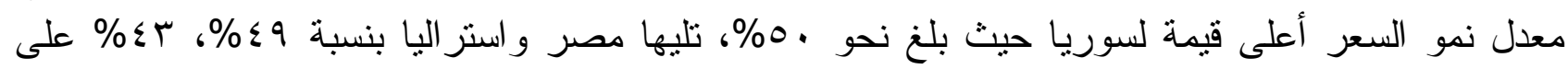
الترتيب، وذللك خلال نفس الفترة.

جدول ( • 1) النصيب السوقي لأهم الدول المنافسة لصادر ات الفراولة المصرية في السوق السعودي

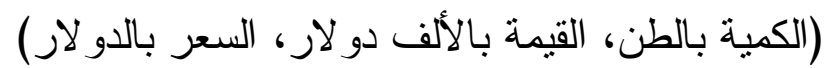

\begin{tabular}{|c|c|c|c|c|c|c|c|c|c|c|c|c|}
\hline \multirow[b]{2}{*}{ معدل } & \multirow{2}{*}{ نمو } & \multicolumn{5}{|c|}{ 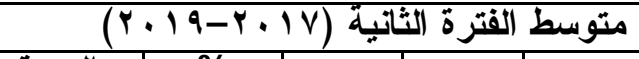 } & \multicolumn{5}{|c|}{ 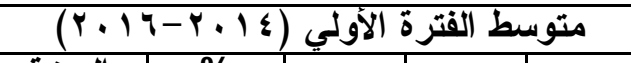 } & \multirow[b]{2}{*}{ 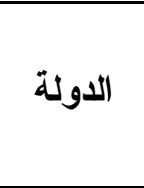 } \\
\hline & & الستافيّية & 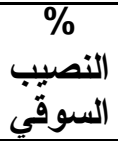 & السعر & القيمة & 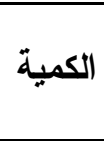 & التنافسية & 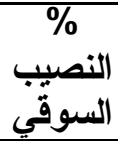 & السعر & القيمة & 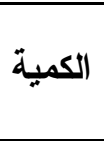 & \\
\hline 43 & $\begin{array}{l}-72 \\
\end{array}$ & 4.08 & 0.37 & 2850 & 97 & 34 & 4.26 & 7.01 & 2009 & 240 & 120 & استر اليا \\
\hline-100 & -100 & 0.00 & 0.00 & 0 & 0 & 0 & 2.47 & 2.69 & 690 & 20 & 29 & الصين \\
\hline 49 & 870 & 2.00 & 75.86 & 700 & 4886 & 6986 & 2.00 & 42.08 & 469 & 338 & 720 & مصر \\
\hline 33 & -60 & 2.86 & 0.04 & 2009 & 8 & 4 & 3.20 & 0.58 & 1500 & 15 & 10 & لبنان \\
\hline 42 & 67 & 5.43 & 0.05 & 3800 & 19 & 5 & 5.68 & 0.18 & 2667 & 8 & 3 & هولندا \\
\hline 50 & 350 & 2.15 & 0.09 & 1500 & 12 & 8 & 2.13 & 0.12 & 1000 & 2 & 2 & 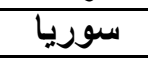 \\
\hline 32 & 275 & 3.15 & 0.49 & 2200 & 99 & 45 & 3.55 & 0.70 & 1667 & 20 & 12 & تونس \\
\hline-16 & 102 & 2.91 & 10.08 & 1360 & 1265 & 928 & 3.44 & 26.94 & 1614 & 741 & 459 & أمريكا \\
\hline 7 & 400 & 4.58 & 0.05 & 3200 & 16 & 5 & 6.39 & 0.06 & 3500 & 3 & 1 & الأمارات \\
\hline-21 & 236 & 2.47 & 12.97 & 1035 & 1226 & 1194 & 2.77 & 20.75 & 1350 & 461 & 355 & دول العالم \\
\hline-23 & 438 & 2.18 & 100 & 940 & 7628 & 9209 & 2.35 & 100 & 1080 & 1848 & 1711 & الإجمالي \\
\hline
\end{tabular}

Source: www.faostat.org. 
ب- المنافسة السعرية داخل السوق السعودي: كما تبين من النتائج الموضحة بالجدول (· • () متوسط أسعار تصدير أهم الدول في السوق السعودي لمحصول الفراولة خلال الفترتين، ويتضح من بيانات الجدول انخفاض منوسط سعر استير اد السعودية خلال

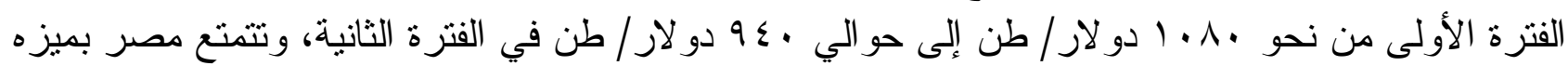

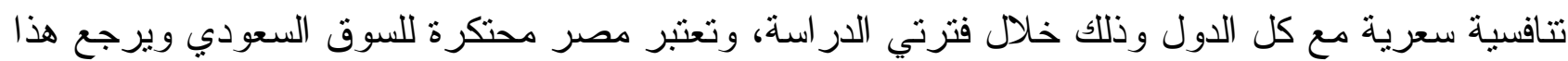
إلى انخفاض السعر نتيجة لقرب المسافة سله

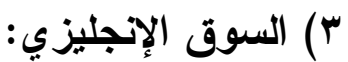

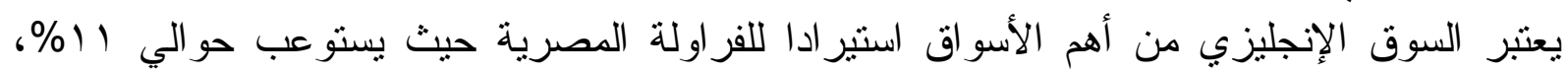

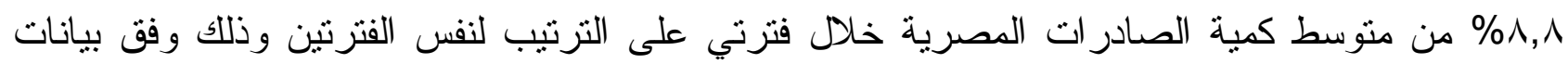

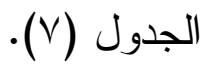

أـ الأصببة السوقية لأهم الدول المنافسة لمصر داخل السوق الإجليزي:

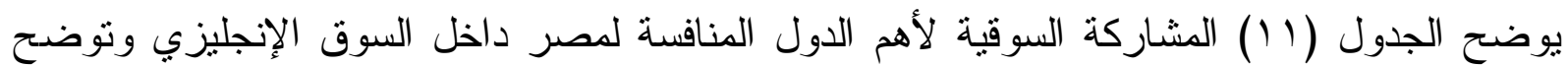

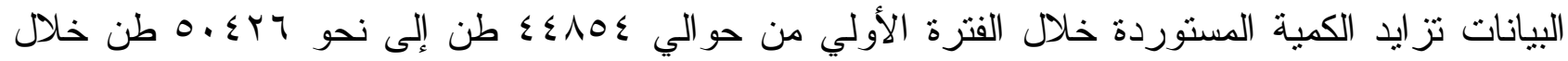

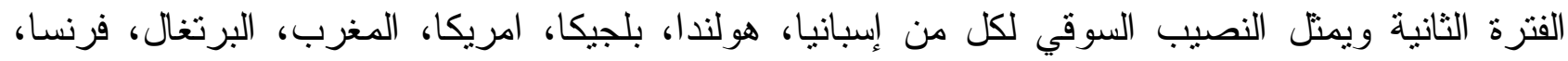

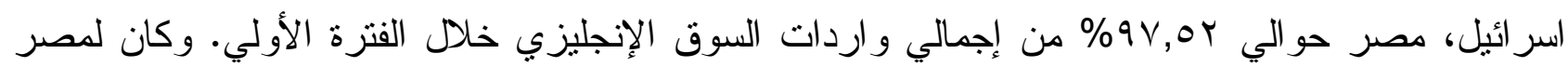

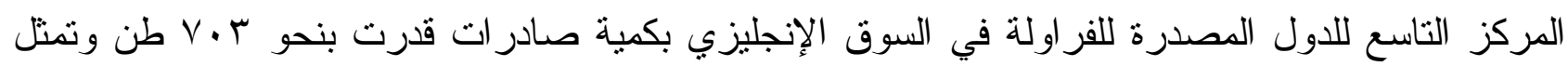

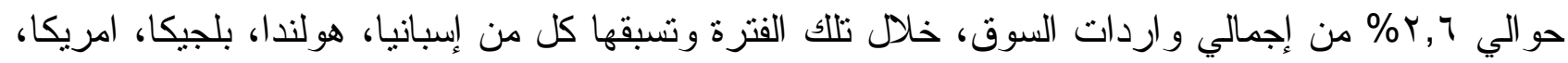

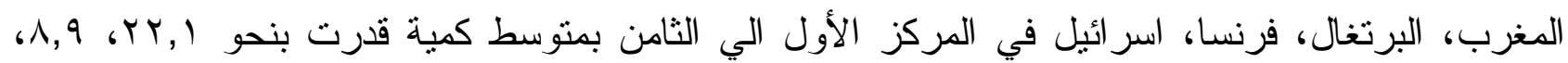

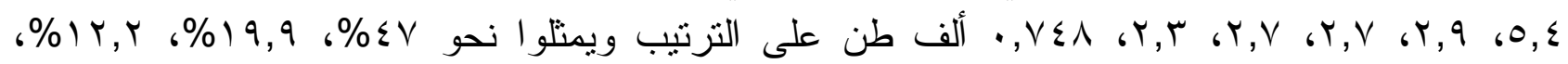

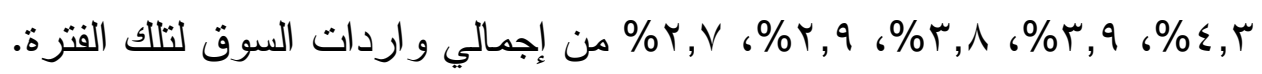
جدول (1 ا ) النصيب السوقي لاهم الدول المنافسة لصادرة

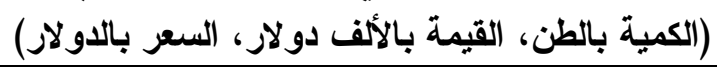

\begin{tabular}{|c|c|c|c|c|c|c|c|c|c|c|c|c|}
\hline \multirow[b]{2}{*}{ معدل } & \multirow[b]{2}{*}{ الكمية } & \multicolumn{5}{|c|}{ 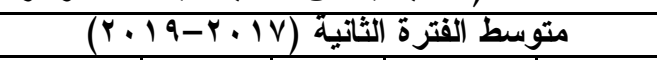 } & \multicolumn{5}{|c|}{ 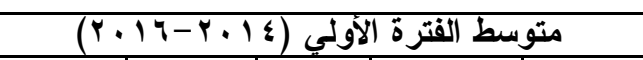 } & \multirow[b]{2}{*}{ 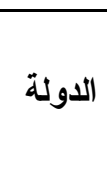 } \\
\hline & & التنافسية & النصيب & السعر & القيمة & 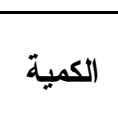 & التنافيّةة & النصبِب & السعر & القيمة & 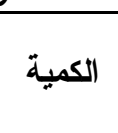 & \\
\hline 6 & -28 & 2.44 & 7.84 & 3947 & 15601 & 3913 & 0.88 & 12.21 & 3744 & 20504 & 5476 & بلجيكا \\
\hline-36 & 310 & 2.00 & 5.71 & 2734 & 7875 & 2880 & 2.00 & 2.57 & 4259 & 2994 & 703 & مصر \\
\hline 50 & -52 & 2.05 & 2.26 & 2868 & 1824 & 636 & 0.45 & 2.96 & 1911 & 2538 & 1328 & فرنسا \\
\hline 209 & -59 & 2.62 & 0.43 & 4427 & 965 & 218 & 0.34 & 2.18 & 1433 & 758 & 529 & ألمانيا \\
\hline-75 & 6445 & 0.48 & 14.93 & 1310 & 9824 & 7527 & 2.23 & 0.26 & 5217 & 600 & 115 & ايرلندا \\
\hline-8 & -58 & 2.51 & 0.62 & 4121 & 1298 & 315 & 2.06 & 2.67 & 4496 & 3363 & 748 & إسر أئيل \\
\hline 14 & 14 & 0.79 & 0.16 & 2148 & 174 & 81 & 0.44 & 0.16 & 1887 & 134 & 71 & إيطاليا \\
\hline 38 & -10 & 2.10 & 0.20 & 5748 & 592 & 1.03 & 0.98 & 4165 & 479 & 115 & 115 & الآردن \\
\hline-15 & 102 & 0.58 & 7.09 & 1573 & 5620 & 3573 & 0.43 & 3.94 & 1847 & 3268 & 1769 & المغرب \\
\hline 32 & -3 & 2.25 & 17.15 & 6145 & 53145 & 8649 & 2.09 & 19.96 & 4635 & 41510 & 8915 & هولندا \\
\hline-8 & -64 & 2.33 & 2.21 & 3646 & 2228 & 611 & 0.93 & 3.82 & 3975 & 6813 & 1714 & البرتغال \\
\hline 49 & 777 & 2.21 & 0.23 & 3316 & 378 & 114 & 0.52 & 0.03 & 2231 & 29 & 13 & أفريقيا \\
\hline 23 & -9 & 2.38 & 38.11 & 3764 & 72343 & 19218 & 0.72 & 47.05 & 3546 & 64282 & 21106 & إسباتيا \\
\hline 2 & -12 & 2.15 & 3.39 & 3155 & 5389 & 1708 & 0.72 & 4.34 & 3587 & 6013 & 1948 & أمريكا \\
\hline 53 & 218 & 2.12 & 2.67 & 5800 & 4872 & 840 & 0.89 & 0.59 & 3800 & 1003 & 264 & البافلّي \\
\hline 8 & 12 & 2.27 & 100 & 3472 & 175128 & 50426 & 0.81 & 100 & 3440 & 154288 & 44854 & الإجمالى \\
\hline
\end{tabular}

Source: www.faostat.org. 
در اسة تحليلية للوضع التنافسي لصادرات الفراولة المصرية في أهم الأسواق العالمبة

أما بالنسبة للفترة الثانية ويمثل النصيب السوقي لكل من إسبانيا، هولندا، ايرلندا، بلجيكا، المغرب، النها،

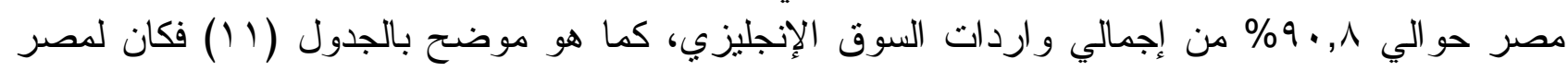

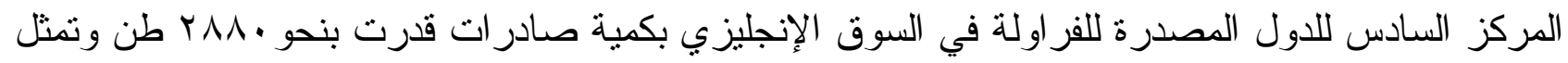
حو الي Vo,V\% من إجمالي واردات السوق، خلال تللك الفتزة وتسبقها كل إسبانيا، هولندا، ايرلندا، بلجيكا،

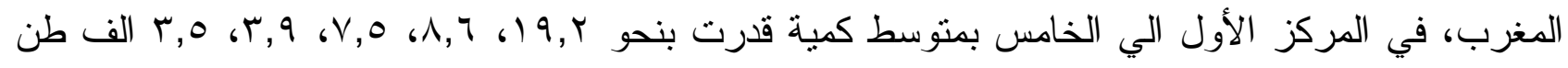

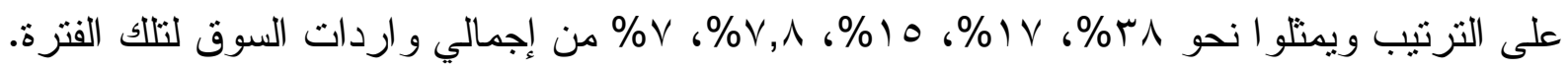

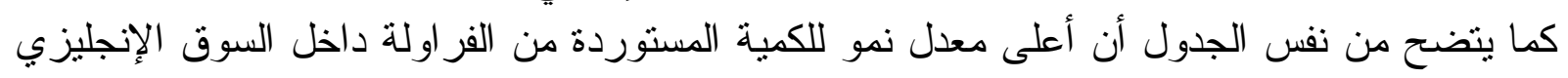

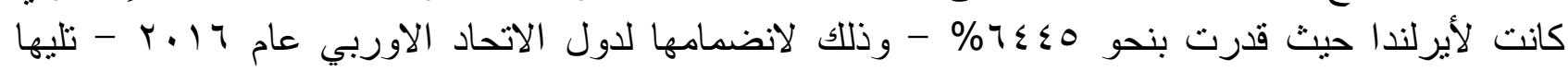

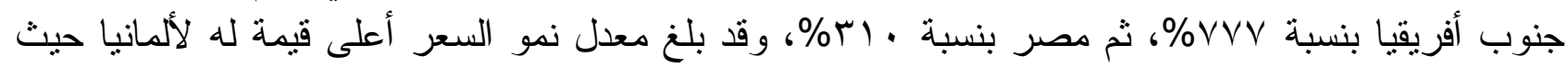

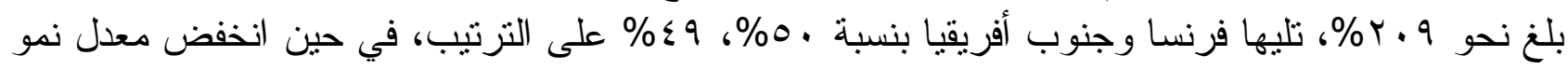

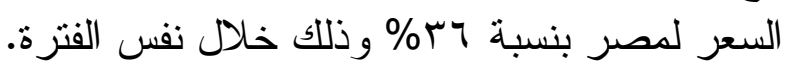

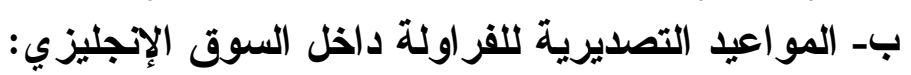

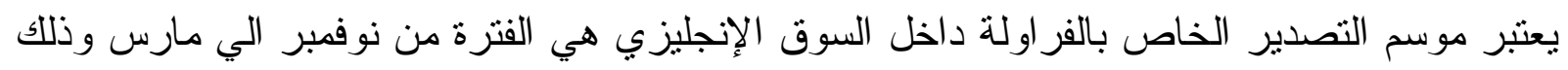

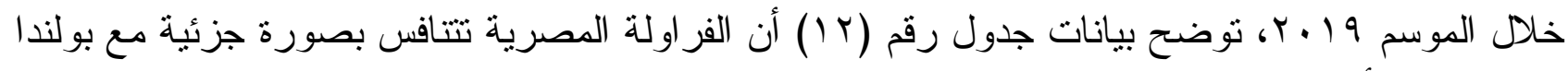
و إسر ائيل والأردن، في حين تتنافس مصر منافسة كلية داخل السوق الإنجليزي مع كل من فرنسا، هولندا،

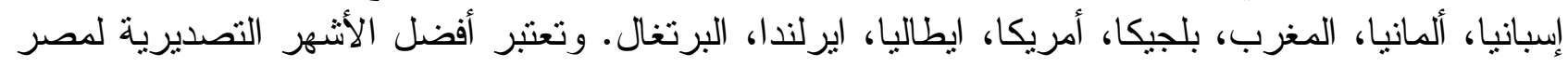

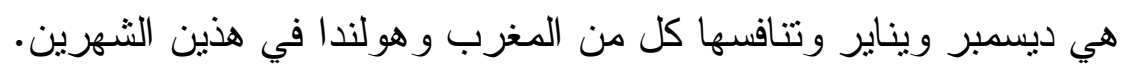
ج- المنافسة السعرية داخل السوق الإنجليزي:

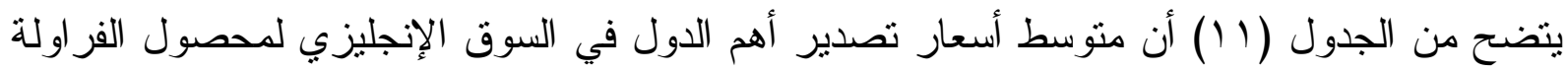

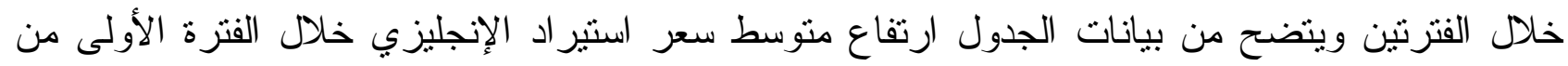

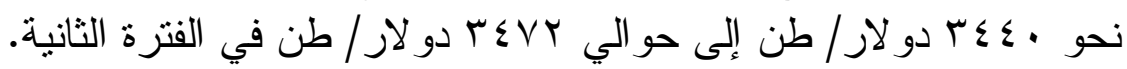

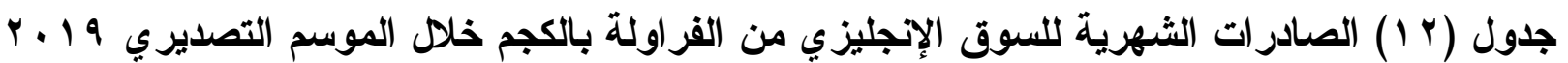

\begin{tabular}{|c|c|c|c|c|c|c|c|c|c|c|c|c|}
\hline Dec & Nov & Oct & Sep & Aug & Jul & Jun & May & Apr & Mar & Feb & Jan & الاولة \\
\hline 689 & 438 & 285 & 31 & 53 & 474 & 3265 & 33639 & 101611 & 49775 & 13356 & 804 & إسبانيا \\
\hline 14795 & 17811 & 23114 & 1912 & 2197 & 11235 & 4172 & 3064 & 3369 & 1417 & 2505 & 1439 & هولندا \\
\hline 7329 & 1815 & & & & & & 63 & 3220 & 26169 & 22142 & 11826 & المغزب \\
\hline 1462 & 5329 & 4568 & 3005 & 2889 & 9967 & 2023 & 3826 & 1786 & 2176 & 1822 & 1292 & بلجيكا \\
\hline 6570 & 171 & & & & & & & & 174 & 2713 & 9220 & مصر \\
\hline 472 & 363 & 444 & 527 & 1656 & 7085 & 2517 & 1062 & 316 & 323 & 311 & 60 & أمريكا \\
\hline 367 & 642 & 805 & 1299 & 1049 & 792 & 1693 & 1106 & 651 & 835 & 911 & 547 & ايرلندا \\
\hline 330 & 119 & 179 & 323 & 36 & 72 & 1168 & 975 & 1719 & 1846 & 2037 & 941 & فُزنسا \\
\hline 3 & 3 & & 1 & 6 & 355 & 35 & 1292 & 1188 & 2523 & 356 & & ألمانيا \\
\hline & & 4 & & & 8 & 94 & 784 & 555 & 212 & 156 & 12 & البرتغال \\
\hline & 36 & 124 & & & 91 & 12 & 0 & 80 & 7 & 256 & 650 & إيطاليا \\
\hline & & 502 & 4 & & & 23 & & & & & 238 & بولندا \\
\hline 451 & & & & & & & & & & 112 & 141 & إسر ائيل \\
\hline 470 & 76 & & & & & & & & & 32 & 98 & ألأردن \\
\hline
\end{tabular}

المصدر: الهيئة العامة للرقابة على الصادرات و الواردات، قطاع التجارة الخارجية.

تفقد مصر الميزة التنافسية السعرية داخل السوق الإنجليزي خلال الفترة الأولي وتتافسها معظم الدول

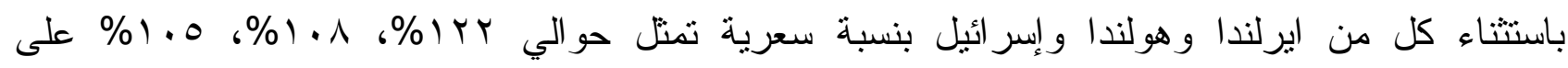
الترتيب، وبالنسبة للفترة الثانية فتتمتع مصر بميزه سعرية مع معظم الدول باستثناء كل من إيطاليا و المغرب

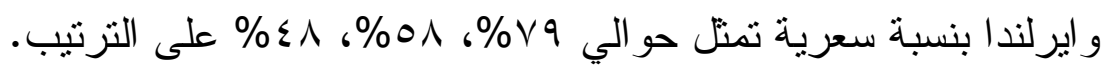




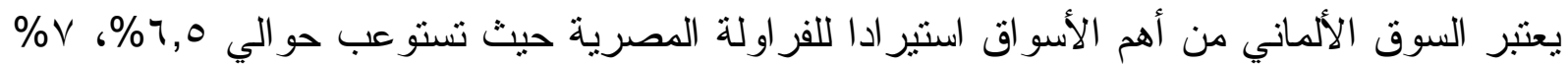

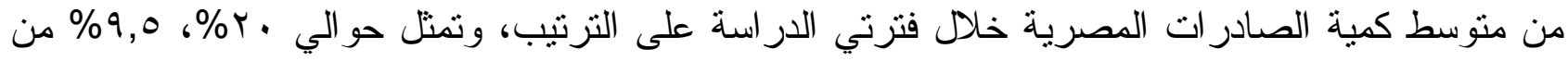

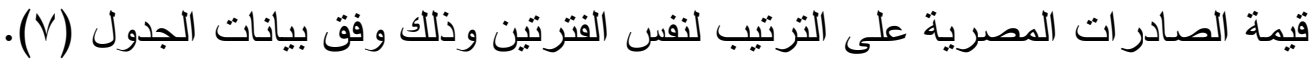
أـ الأنصبة السوقية لأهم الدول المنافسة لمصر داخل التل السوق الألماني:

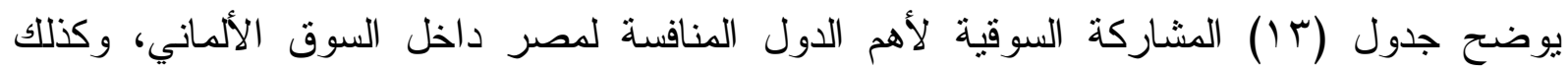

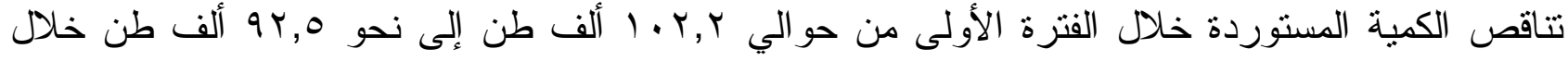

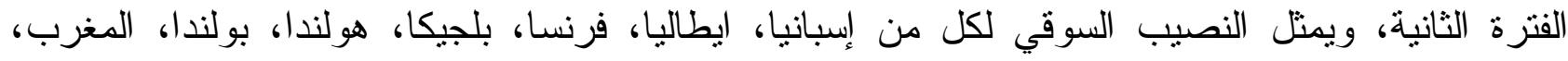

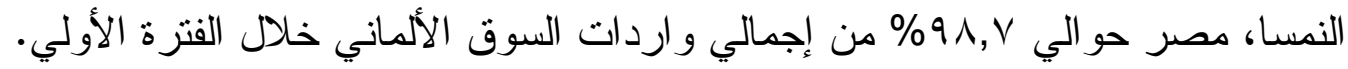
جدول (ب I) النصيب السوقي لاهم الدول المنافسة لصادرات الفراولة المصرية في السوق الألماني

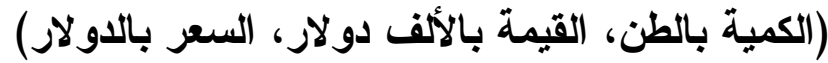

\begin{tabular}{|c|c|c|c|c|c|c|c|c|c|c|c|c|}
\hline \multirow[b]{2}{*}{ السعو } & \multirow[b]{2}{*}{ نمعد } & \multicolumn{5}{|c|}{ 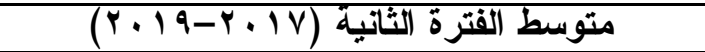 } & \multicolumn{5}{|c|}{ 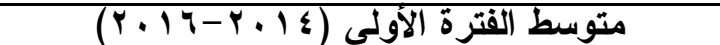 } & \\
\hline & & الستافينية & 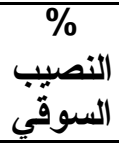 & 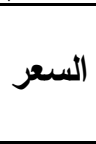 & القيمة & 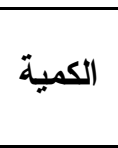 & التنافسيّة & $\begin{array}{c}\% \\
\text { السوقِيب } \\
\text { السوقي }\end{array}$ & 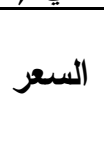 & القيمة & 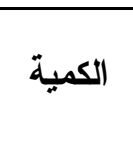 & \\
\hline-24 & -11 & 0.94 & 0.68 & 1550 & 961 & 622 & 0.69 & 0.69 & 2036 & 1415 & 691 & النمسا \\
\hline 100 & -59 & 2.44 & 3.09 & 2680 & 7561 & 2826 & 0.46 & 6.87 & 1343 & 9338 & 6914 & بلجيكا بل بل با \\
\hline-19 & 675 & 2.96 & 0.03 & 3650 & 113 & 31 & 2.53 & 0.00 & 4500 & 18 & 4 & قبرص \\
\hline 76 & 1461 & 0.73 & 0.53 & 1360 & 657 & 484 & 0.26 & 0.03 & 774 & 24 & 31 & التشيك \\
\hline-37 & 450 & 2.00 & 2.49 & 1860 & 4243 & 2282 & 2.00 & 0.41 & 2947 & 1223 & 415 & مصر \\
\hline 32 & -39 & 2.37 & 5.93 & 2550 & 13842 & 5432 & 0.66 & 8.79 & 1935 & 17169 & 8891 & فزرنسا \\
\hline 6 & 2473 & 2.35 & 2.24 & 2410 & 2735 & 1132 & 0.77 & 0.04 & 2273 & 100 & 44 & اليونان \\
\hline 10 & -10 & 2.53 & 9.31 & 2840 & 24242 & 8522 & 0.87 & 9.32 & 2578 & 24316 & 9432 & إيطاليا \\
\hline 41 & 35 & 2.33 & 3.39 & 2470 & 7659 & 3104 & 0.60 & 2.28 & 1758 & 4055 & 2356 & المغرب \\
\hline 21 & 27 & 2.28 & 5.81 & 4250 & 22585 & 5320 & 2.19 & 4.15 & 3511 & 14758 & 4203 & هولندا \\
\hline 39 & -20 & 0.58 & 3.41 & 1070 & 3345 & 3119 & 0.26 & 3.87 & 768 & 3507 & 3915 & بولندا \\
\hline 42 & -9 & 2.37 & 63.00 & 2550 & 147259 & 57668 & 0.61 & 62.67 & 1790 & 113518 & 63421 & إسباتيا \\
\hline 52 & -45 & 2.70 & 0.21 & 3170 & 608 & 192 & 0.71 & 0.35 & 2085 & 734 & 352 & إنجلترا \\
\hline 80 & 50 & 2.13 & 0.87 & 2110 & 1682 & 798 & 0.40 & 0.52 & 1173 & 623 & 531 & العالم \\
\hline 38 & -10 & 2.40 & 100 & 2590 & 237487 & 91532 & 0.64 & 100 & 1880 & 190298 & 101198 & الإجمالي \\
\hline
\end{tabular}

Source: www.faostat.org.

وكان لمصر المركز التاسع للدول المصدرة للفراولة في السوق الألماني خلا الفترة الأولى بكمية

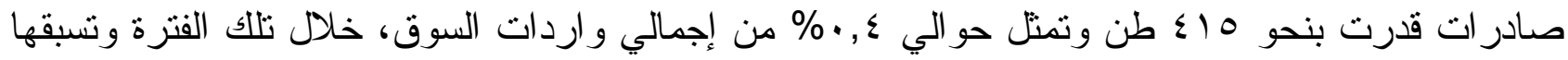

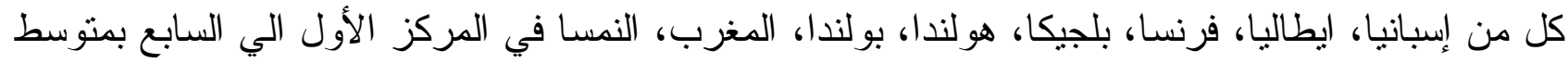

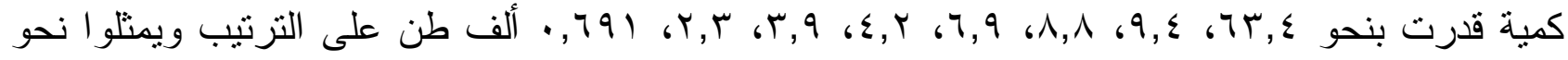

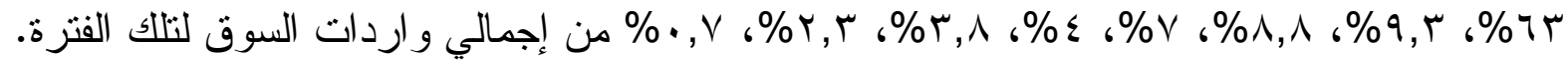

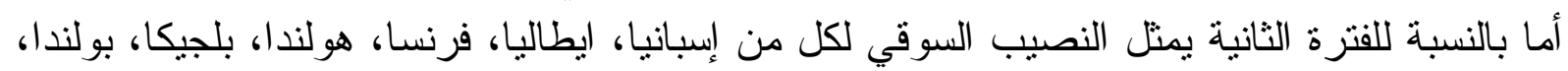

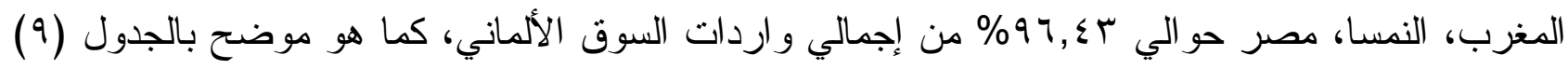

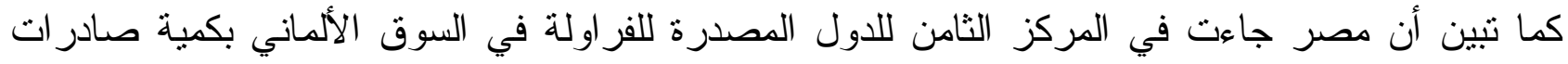
قدرت بنحو r r r طن، تمثل نحو بr,0\% من إجمالي واردات السوق، لنفس الفترة وتسبقها كل من إسبانيا، ايطاليا، فرنسا، هولندا، بلجيكا، بولندا، المغرب، في المركز الأول إلي السابع بمتوسط كمية قدرت بنحو 
لدر اسة تحليلية للوضع التنافيي لصادر ات الفراولة المصرية في أهم الأسواق العالمية

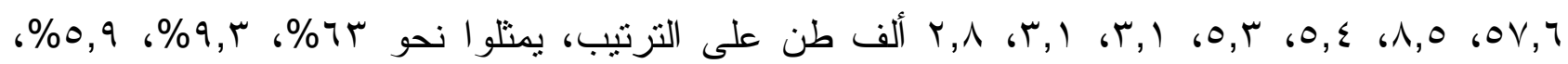

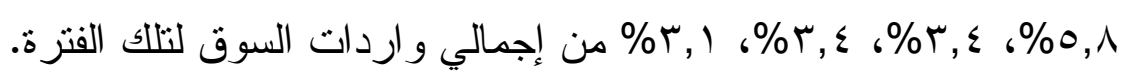

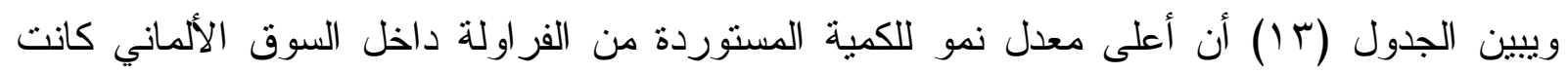

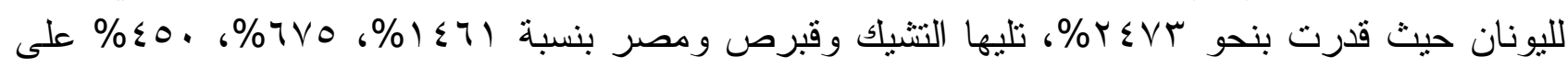

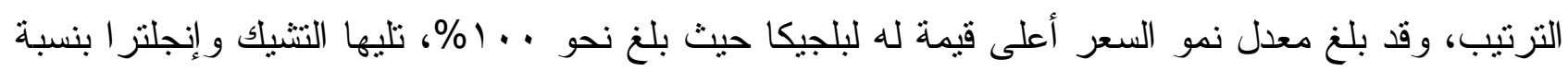

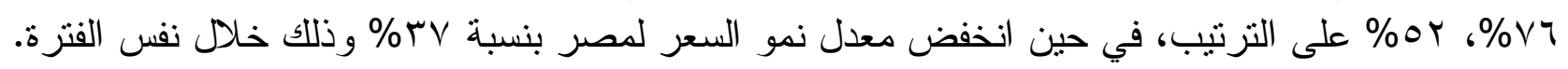

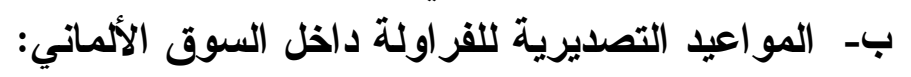
يعتبر موسم التصدير الخاص بالفراولة داخل السوق الألماني هي الفترة من نوفمبر إلى فبر اير وذلك إلك

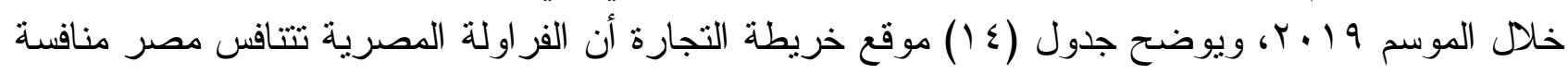

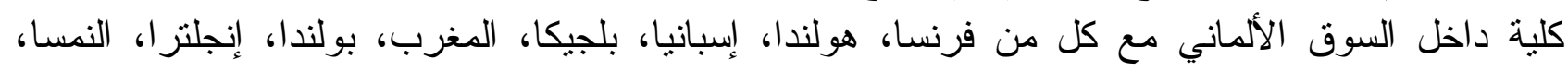

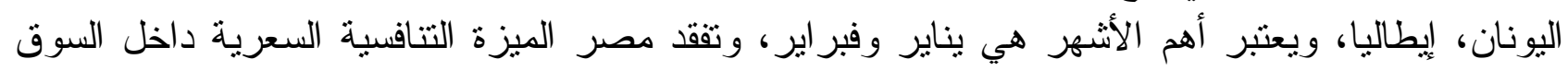

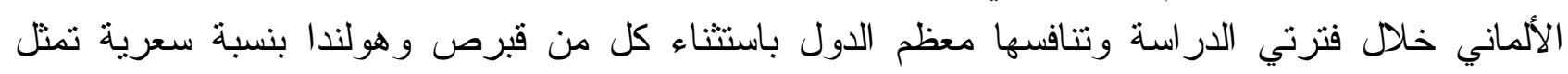

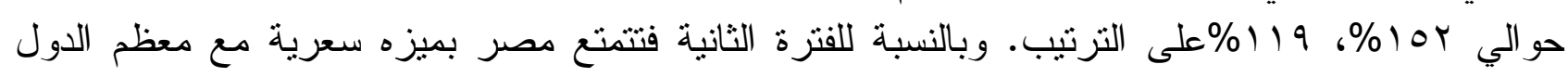

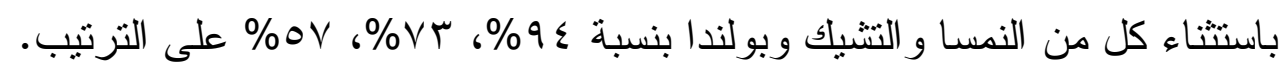

ج- المنافسة السعرية داخل السوق الألماني:

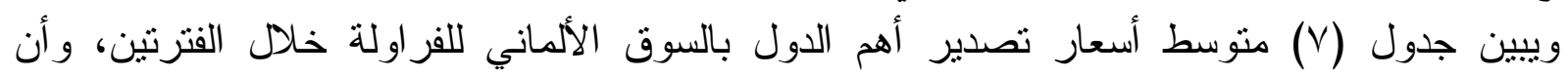

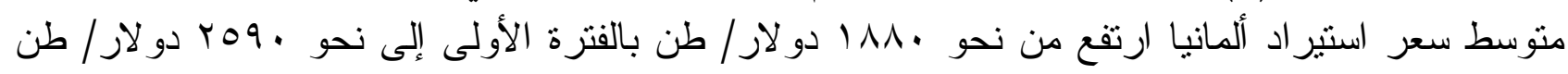
بالفتزة الثانية.

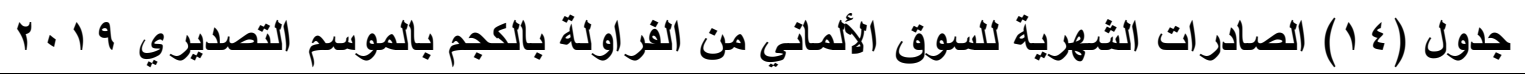

\begin{tabular}{|c|c|c|c|c|c|c|c|c|c|c|c|c|}
\hline Dec & $\begin{array}{l}\text { Nov } \\
\end{array}$ & Oct & Sep & Aug & Jul & Jun & May & Apr & Mar & Feb & Jan & الاولة \\
\hline 422 & 85 & 114 & 33 & 954 & 2789 & 73348 & 213809 & 278838 & 112775 & 39051 & 2088 & إسبانيا \\
\hline 5766 & 2187 & 5453 & 4535 & 5345 & 4410 & 23624 & 21868 & 10896 & 1146 & 1230 & 1824 & هولندا \\
\hline 353 & 432 & 1429 & 1476 & 753 & 378 & 4310 & 33365 & 18564 & 2386 & 322 & 180 & ايطاليا \\
\hline & 226 & 241 & 188 & 935 & 6245 & 28358 & 717 & 0 & & 346 & 60 & بولندا \\
\hline 566 & 62 & & & & & & & 2989 & 16568 & 9241 & 5894 & المغرب \\
\hline 1807 & 1394 & 2023 & 3175 & 1356 & 613 & 13066 & 8111 & 733 & 179 & 261 & 588 & بلجيكا \\
\hline 187 & 36 & 11 & 26 & 6 & 157 & 2573 & 7007 & 10341 & 5490 & 2782 & 392 & فزنسا \\
\hline & 110 & & & & 6 & 191 & 928 & 2199 & 2974 & 783 & 196 & اليونان \\
\hline 3696 & 210 & & & & & & & & & 92 & 1126 & مصر \\
\hline & & 4 & 0 & 18 & 424 & 1630 & 1459 & 489 & 141 & 67 & 2 & النمسا \\
\hline 53 & 17 & & & & & & 309 & 410 & 236 & 5 & 31 & إنجلترا \\
\hline & & 0 & & 1014 & 1 & 0 & & & 0 & & & الانماررك \\
\hline
\end{tabular}

المصدر: الهيئة العامة للرقابة على الصادرات والواردات، قطاع التجارة الخارجية.

ثالثاً: قوة التصدير والاعتماد على التصدير للفراولة المصرية في أهم الأسواق الاستير ادية:

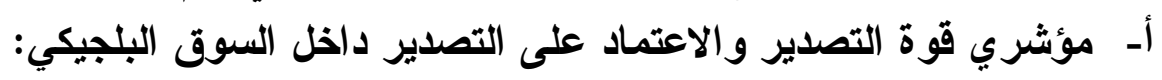

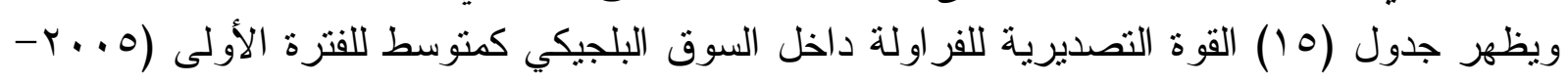

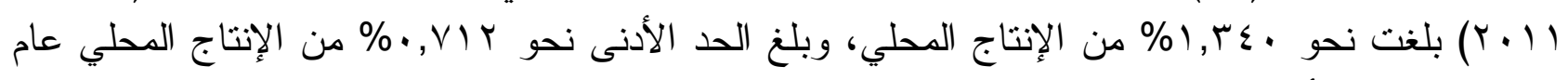

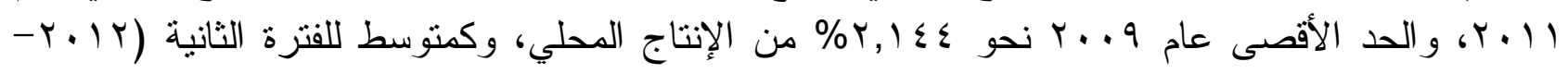

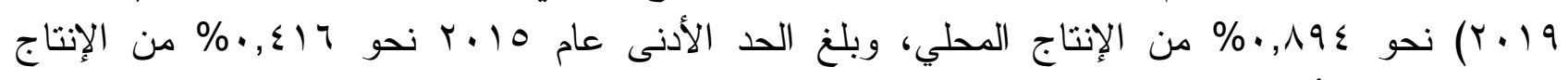

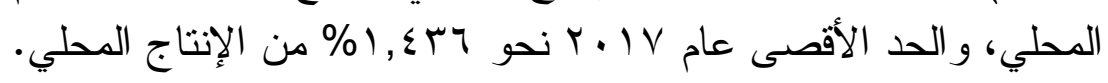




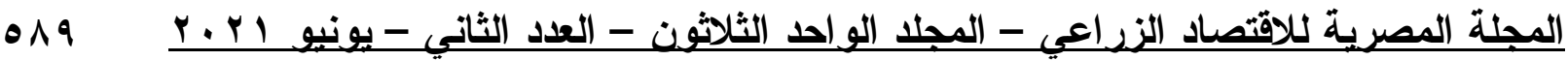

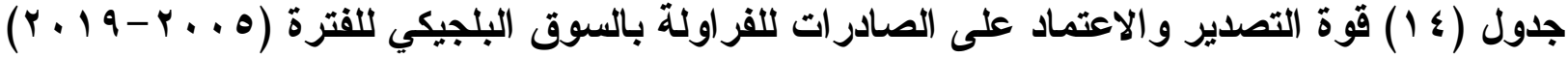

\begin{tabular}{|c|c|c|c|c|}
\hline على الصنادرات الاعتماد & مؤشُر قُوة & كمية الإنتاج & كلية الصنادرات البلجيكي & السنوات \\
\hline 1.363 & 1.381 & 104971 & 1450 & 2004 \\
\hline 1.753 & 1.784 & 100000 & 1784 & 2005 \\
\hline 0.932 & 0.941 & 128349 & 1208 & 2006 \\
\hline 1.070 & 1.082 & 174414 & 1887 & 2007 \\
\hline 1.236 & 1.251 & 200254 & 2506 & 2008 \\
\hline 2.099 & 2.144 & 242776 & 5204 & 2009 \\
\hline 1.407 & 1.427 & 238432 & 3402 & 2010 \\
\hline 0.707 & 0.712 & 240284 & 1711 & 2011 \\
\hline 1.321 & 1.340 & 178685 & 2394 & متوسط الفترة $2011-2004)$ \\
\hline 0.509 & 0.511 & 242297 & 1239 & 2012 \\
\hline 0.533 & 0.536 & 262432 & 1407 & 2013 \\
\hline 0.814 & 0.821 & 283471 & 2327 & 2014 \\
\hline 0.418 & 0.420 & 435344 & 1829 & 2015 \\
\hline 0.762 & 0.767 & 378960 & 2908 & 2016 \\
\hline 1.416 & 1.436 & 318950 & 4580 & 2017 \\
\hline 1.198 & 1.212 & 445106 & 5396 & 2018 \\
\hline 1.199 & 1.214 & 460245 & 5587 & 2019 \\
\hline 0.886 & 0.894 & 353351 & 3159 & متوسط الفترة \\
\hline
\end{tabular}

Source: www.faostat.org.

ب- مؤشري قوة التصدير والاعتماد على التصدير داخل السوق السعودي:

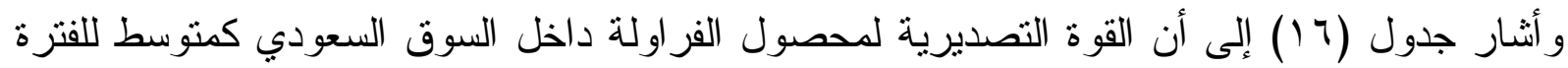

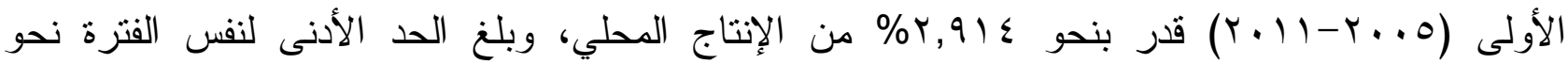

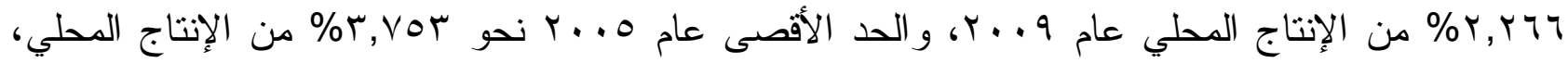

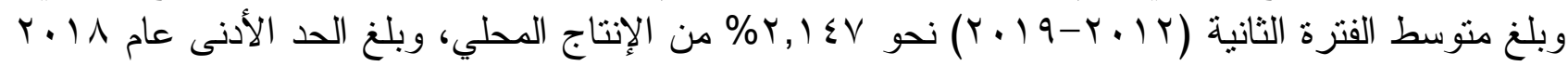

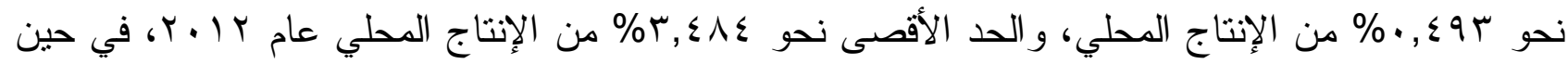

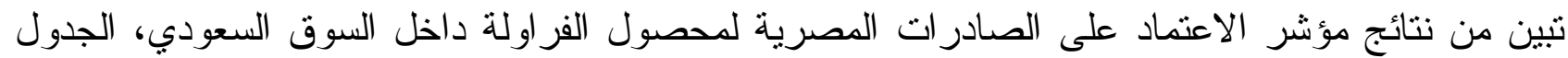

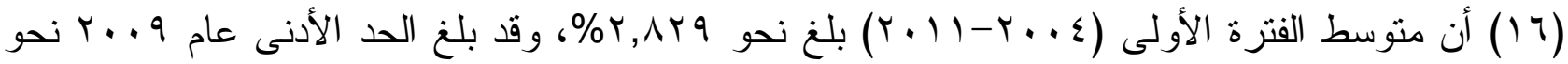

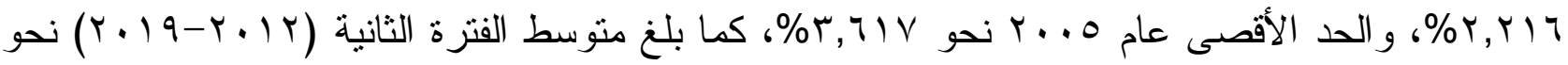

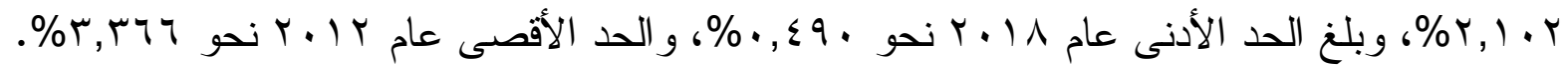
ج- مؤشري قوة التصدير والاعتماد على التصدير داخل السوق الإن الإنجليزي:

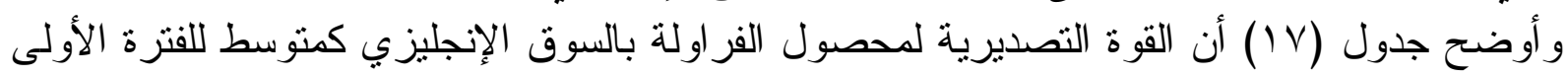

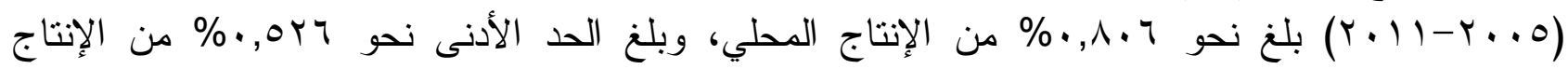

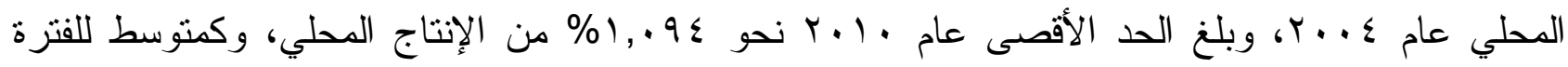

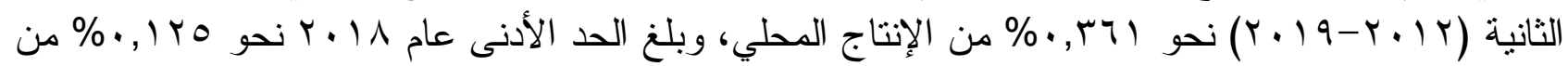

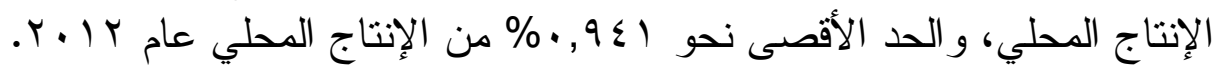

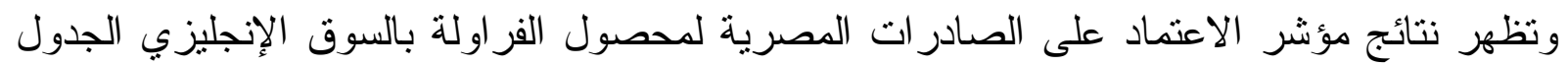

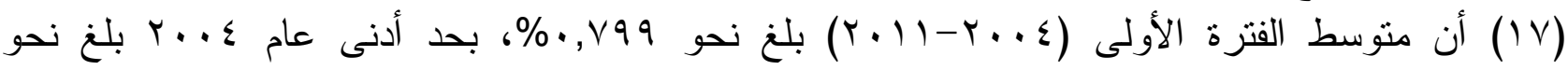

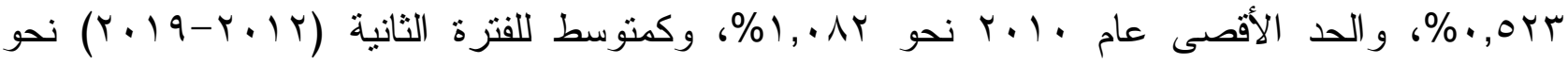

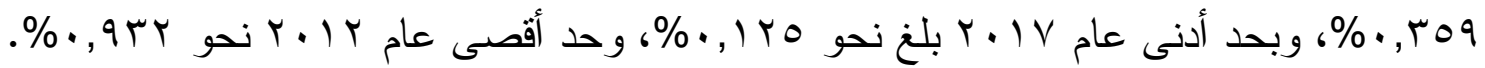


دو داسة تحليلية للوضع التنافسي لصادرات الفراولة المصرية في أهم الأسواق العالمية

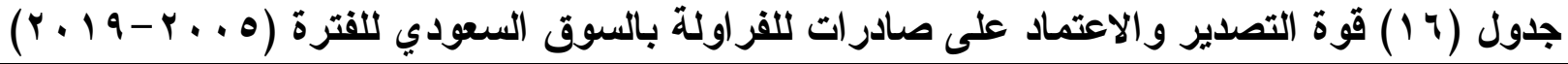

\begin{tabular}{|c|c|c|c|c|}
\hline على الصادر الاعتماد & مؤشر قُوة & كميَّة الإلتاج & كمية الصادرات & السنوات \\
\hline 3.293 & 3.405 & 104971 & 3574 & 2004 \\
\hline 3.617 & 3.753 & 100000 & 3753 & 2005 \\
\hline 3.380 & 3.498 & 128349 & 4490 & 2006 \\
\hline 2.596 & 2.665 & 174414 & 4648 & 2007 \\
\hline 2.486 & 2.550 & 200254 & 5106 & 2008 \\
\hline 2.216 & 2.266 & 242776 & 5502 & 2009 \\
\hline 2.680 & 2.753 & 238432 & 6565 & 2010 \\
\hline 2.363 & 2.420 & 240284 & 5816 & 2011 \\
\hline 2.829 & 2.914 & 178685 & 4932 & متوسط الفترة \\
\hline 3.366 & 3.484 & 242297 & 8441 & 2012 \\
\hline 2.652 & 2.724 & 262432 & 7148 & 2013 \\
\hline 2.741 & 2.818 & 283471 & 7988 & 2014 \\
\hline 1.938 & 1.977 & 435344 & 8605 & 2015 \\
\hline 2.441 & 2.502 & 378960 & 9481 & 2016 \\
\hline 2.206 & 2.256 & 318950 & 7196 & 2017 \\
\hline 0.490 & 0.493 & 445106 & 2193 & 2018 \\
\hline 2.054 & 2.097 & 460245 & 9651 & 2019 \\
\hline 2.102 & 2.147 & 353351 & 7588 & متوسط الفترة \\
\hline
\end{tabular}

Source: www.faostat.org.

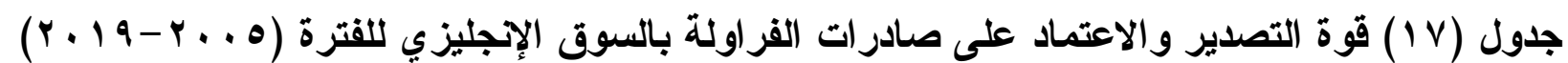

\begin{tabular}{|c|c|c|c|c|}
\hline على الصنادرات الاعتماد & مؤشر قُوة & كمية الإلتاج & كمية الصادير ات الإنجليزي & السنوات \\
\hline 0.523 & 0.526 & 104971 & 552 & 2004 \\
\hline 0.554 & 0.557 & 100000 & 557 & 2005 \\
\hline 0.775 & 0.781 & 128349 & 1003 & 2006 \\
\hline 0.893 & 0.901 & 174414 & 1571 & 2007 \\
\hline 0.728 & 0.733 & 200254 & 1468 & 2008 \\
\hline 1.060 & 1.072 & 242776 & 2602 & 2009 \\
\hline 1.082 & 1.094 & 238432 & 2608 & 2010 \\
\hline 0.778 & 0.784 & 240284 & 1885 & 2011 \\
\hline 0.799 & 0.806 & 178685 & 12246 & متوسط الفترة \\
\hline 0.932 & 0.941 & 242297 & 2279 & 2012 \\
\hline 0.500 & 0.502 & 262432 & 1318 & 2013 \\
\hline 0.496 & 0.498 & 283471 & 1413 & 2014 \\
\hline 0.218 & 0.218 & 435344 & 951 & 2015 \\
\hline 0.176 & 0.177 & 378960 & 669 & 2016 \\
\hline 0.125 & 0.125 & 318950 & 400 & 2017 \\
\hline 0.172 & 0.172 & 445106 & 767 & 2018 \\
\hline 0.253 & 0.254 & 460245 & 1167 & 2019 \\
\hline 0.359 & 0.361 & 353351 & 1121 & متوسط الفترة \\
\hline
\end{tabular}

Source: www.faostat.org.

د- مؤشري قوة التصدير والاعتماد على التصدير داخل السوق الألماني:

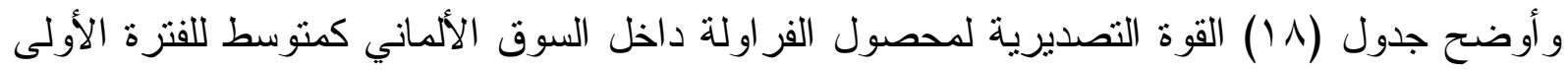

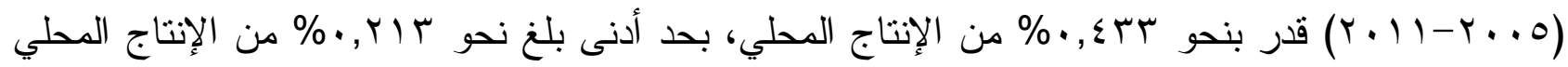

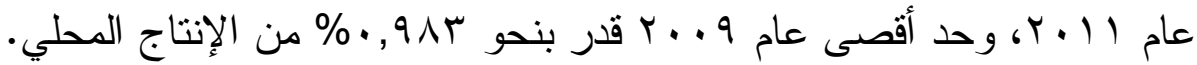




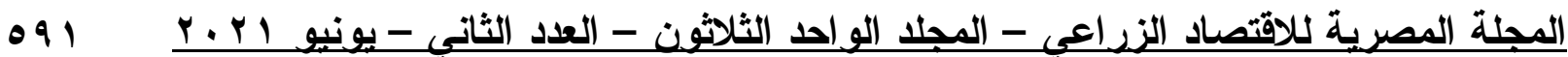

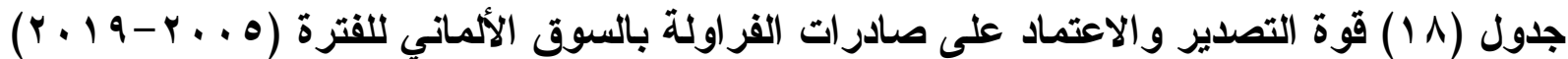

\begin{tabular}{|c|c|c|c|c|}
\hline على الصادر الاعتماد & مؤشار قُوة & كمية الإلتاج & كمية الصادرات اللاتماتي & السنوات \\
\hline 0.322 & 0.323 & 104971 & 339 & 2004 \\
\hline 0.286 & 0.287 & 100000 & 287 & 2005 \\
\hline 0.483 & 0.485 & 128349 & 623 & 2006 \\
\hline 0.472 & 0.475 & 174414 & 828 & 2007 \\
\hline 0.315 & 0.316 & 200254 & 633 & 2008 \\
\hline 0.973 & 0.983 & 242776 & 2386 & 2009 \\
\hline 0.382 & 0.384 & 238432 & 915 & 2010 \\
\hline 0.213 & 0.213 & 240284 & 513 & 2011 \\
\hline 0.431 & 0.433 & 178685 & 815.5 & متوسط الفترة \\
\hline 0.442 & 0.444 & 242297 & 1075 & 2012 \\
\hline 0.318 & 0.319 & 262432 & 838 & 2013 \\
\hline 0.637 & 0.641 & 283471 & 1816 & 2014 \\
\hline 0.526 & 0.529 & 435344 & 2301 & 2015 \\
\hline 0.482 & 0.485 & 378960 & 1837 & 2016 \\
\hline 0.950 & 0.959 & 318950 & 3058 & 2017 \\
\hline 0.733 & 0.739 & 445106 & 3288 & 2018 \\
\hline 0.758 & 0.764 & 460245 & 3515 & 2019 \\
\hline 0.623 & 0.627 & 353351 & 2216 & متوسط الفترة \\
\hline
\end{tabular}

\section{Source: www.faostat.org.}

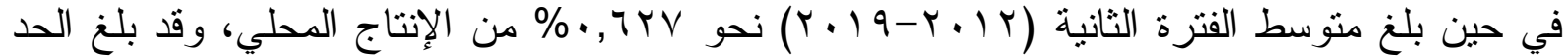
الأدنى عام r| • ب نحو 9 (1, • \% من الإنتاج المحلي، و الحد الأقصى نحو 909, • \% من الإنتاج المحلي عام

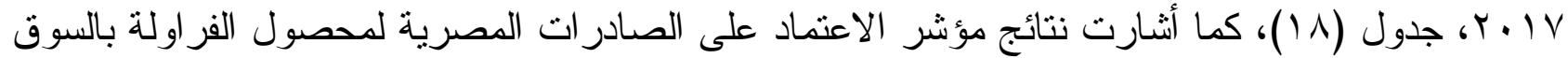

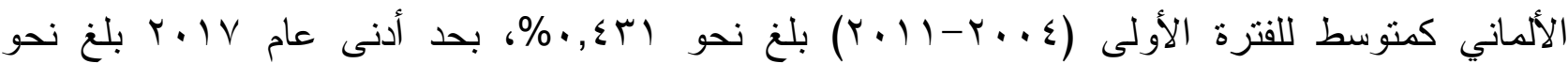

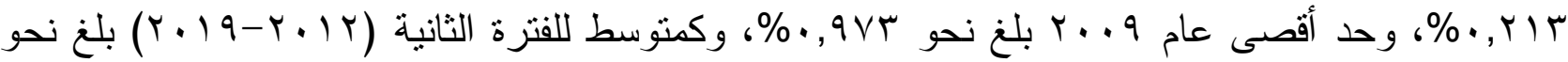

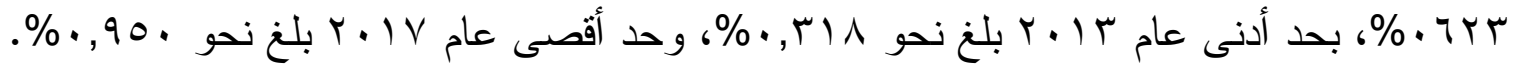
الملخص:

ومما سبق تبين أن الأسواق السعودية جاءت في المركز الأول بالنسبة لقيمة مؤشر قوة صادر ات مصر

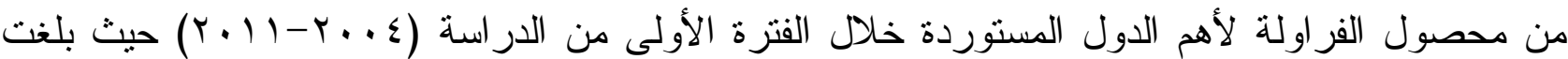

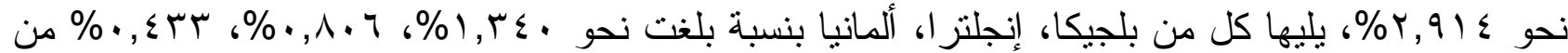
إجمالي الإنتاج المصري لمحصول الفراولة، كما جاءت السعودية أيضا في المركز الأول بالنسبة لنسبة

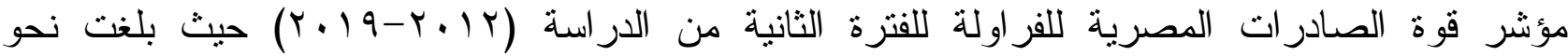

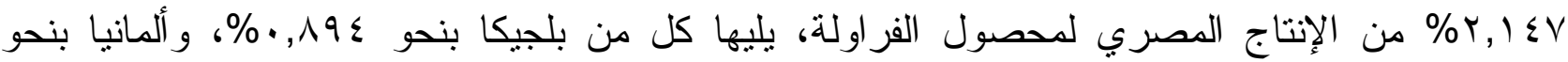

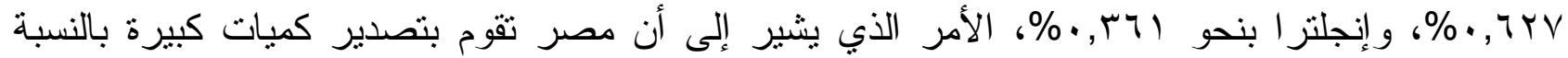
لإنتاجها من الفر اولة. كما تبين أن الأسواق السعودية جاءت في المركز الأول بالنسبة لنسبة مؤشر الاعتماد على صادر ات

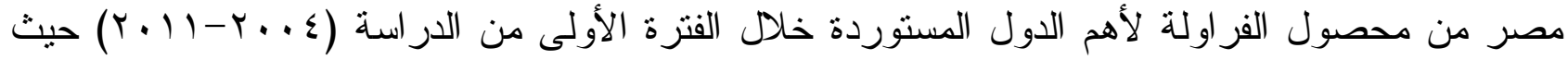




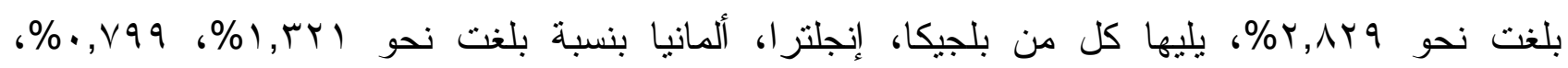

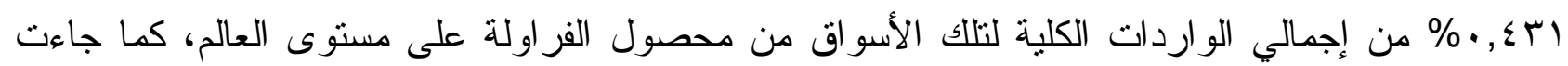
السعودية أيضا في المركز الأول بالنسبة لنسبة مؤشر الاعتماد على الفراولة المصرية للفترة الثانية من

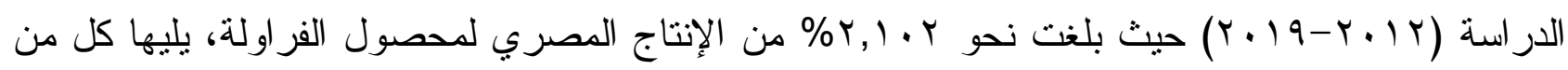

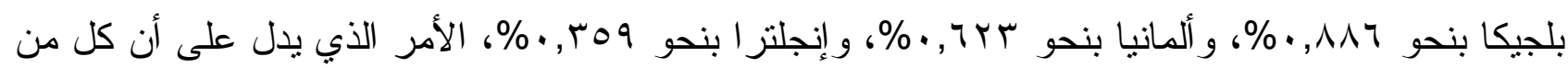
أسو اق السعودية، بلجيكا و ألمانيا يعتمدو ا بنسبة كبيرة على الصادر ات المصرية من الفراولة.

التوصيات:

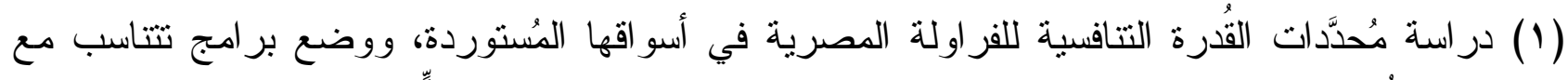
دعم القُرات التنافية لهذا المحصول، من شأنها العمل على زيادة كلٍٍ من قيمة وكمية صادراته، و القدرة على النفاذ إلى الأسو اق بشكلٍ أفضل، وفتح أسواق جديدة أمامه، وبالتالي تعزيز قدرته التنافسية في تلك الأسو اق و الأسواق الو اعدة أمامها، مع ضرورة الحفاظ على الأسواق الحالية وتتمية الصادر ات المصرية من الفر اولة فيها، و العمل على زيادة حجم صادر ات مصر من الفر اولة لسوق ألمانيا. (r) ضرورة تتمية صادر ات مصر للدول العربية من الفراولة المصرية، والارتقاء بها لتكون من أهم الدول الو اعدة لصادر ات مصر من الفر اولة، في ضوء التكامل العربي في المجال الزر اعي. (r) ضرورة الاستفادة من ارتفاع معدل نمو الطلب على الفراولة داخل الأسواق العالمية من خلال زيادة الصادر ات المصرية منها، وتحسين جودنها. ( ) نتجيع إنشاء شركات متخصصة في التصدير بدعم من الدولة، بما يسهم في خلق كيانات قوية في الأسو اق الخار جية. (ه) توفير قاعدة بيانات حكومية تهتم بدر اسة الأسو اق الخارجية، وأهم المنافسين ومو اعيد تصدير هم، بجانب

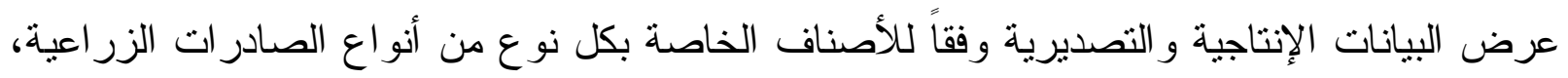
ليستطيع المصدر معرفة الأصناف المطلوبة في الأسواق الخارجية.

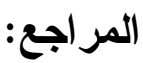
ا. آمال طلبه و آخرون، در اسة تحليلية لأهم المواسم التصديرية للرمان و الفراولة في مصر، مجلة العلوم

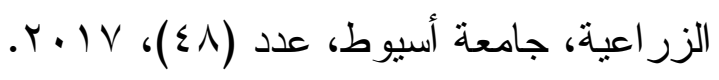
ץ. أمل أحمد سويفي، در اسة اقتصادية تحليلية للصادرات المصرية لمحصول الفراولة باستخدام نموذج

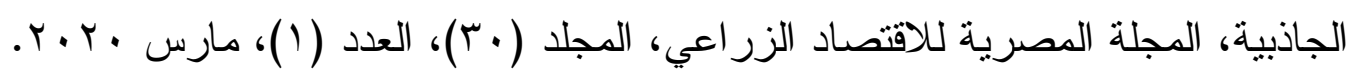
r. إيمان سالم البطران، محددات القرة التنافسية لصادرات الفراولة المصرية في أهم الأسواق العالمية،

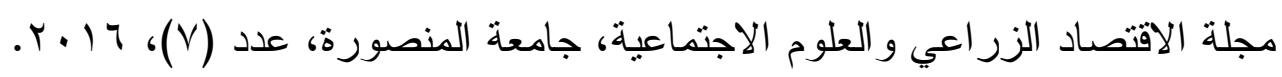
ع. الجهاز المركزي للتعبئة العامة و الاحصاء، نشرة الميز ان الغذائي، أعداد مختلفة. •. جيهان محمد عبد الفتاح، تتمية الصادرات المصرية للخضر لأهم الأسواق العالمية، رسالة دكتور اه، قسم

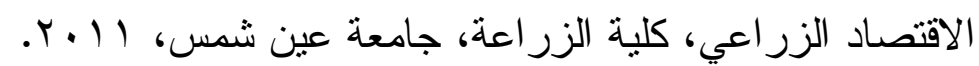
7 ـ ريهام محمد سليمان، اقتصاديات إنتاج محصول الفراولة في محافظة البحيرة، رسالة ماجستير، قسم

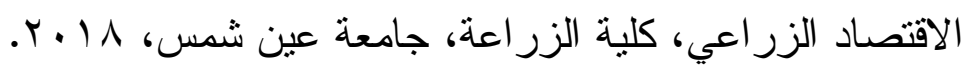


V. شادية صلاح الدين محمد، دراسة اقتصادية لإمكانية تتمية إنتاج وتصدير الفراولة المصرية، المجلة

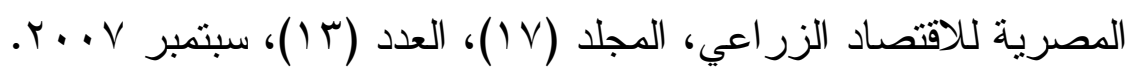

^. مصطفي الثحات (دكتور)، القدرة التتافية ومحددات الطلب الخارجي على الصادرات المصرية من

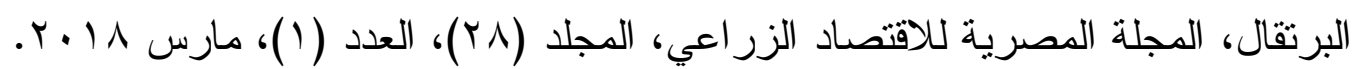

9. منال الخشن، و آخرون، در اسة تحليلية للصادر ات الزر اعية المصرية من الفراولة و العنب إلى الأسواق

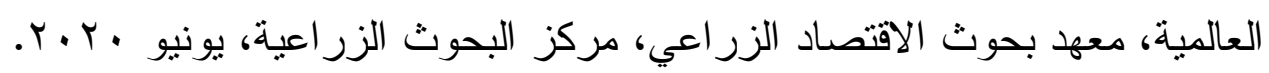

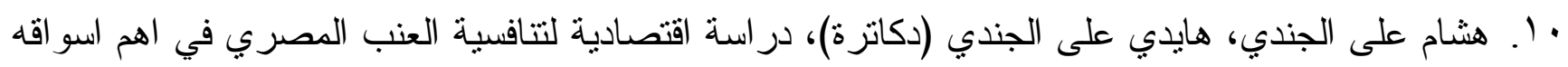

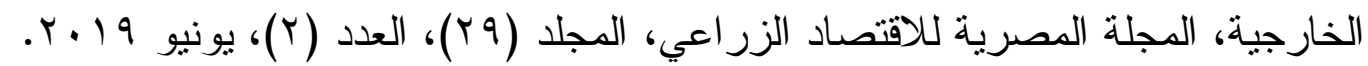

ا ا . الهيئة العامة للرقابة على الصادر ات و الواردات، قطاع التجارة الخارجية.

\title{
12. Www.faostat.org
}

\section{An Analysis of the Competitive Position of Egyptian Strawberry Exports in the World's Most Important Markets}

\author{
Dr. Dina Farouk Enany (Researcher), Dr. Ehab Mohammed Sabri (Doctor) \\ Agricultural Economics Research Institute - Agricultural Research Center
}

\section{Summary}

Saudi markets ranked first in terms of the strength of Egypt's strawberry exports to the most important importing countries during the first period of the study (20042011), with about 2,914\%, followed by Belgium, England, and Germany with about $1,340 \%, 0.806 \%$, and $0.433 \%$ of total Egyptian strawberry crop production, as came Saudi Arabia. It is also in first place for the Egyptian export strength index for strawberries for the second period of the study (2012-2019) with about 2.147\% of Egyptian strawberry crop production, followed by Belgium at $0.894 \%$, Germany at about $0.627 \%$, and England at about 0.361\%, indicating that Egypt exports large quantities for its strawberry production.

It also turns out that the Saudi markets came in first place in relation to the percentage of the index of dependence on Egypt's exports of strawberries to the most important importing countries during the first period of the study (2004-2011) where it reached about 2.829\%, followed by Belgium, England, Germany with about 


\section{$09 \varepsilon$}

$1.321 \%, 0.799 \%, 0.431 \%$ of the total imports of those markets from the strawberry crop worldwide, as well as Saudi Arabia, as well as Saudi Arabia. In first place for the percentage of the Egyptian strawberry dependence index for the second period of the study (2012-2019) where it reached about 2.102\% of Egyptian strawberry crop production, followed by Belgium by about $0.886 \%$, Germany by about $0.623 \%$, and England by about $0.359 \%$, which indicates that both the markets of Saudi Arabia, Belgium and Germany depend significantly on Egyptian exports of strawberries.

Keywords: Market shares, export dates, price competition. 